\title{
Modulation of the Root Microbiome by Plant Molecules: The Basis for Targeted Disease Suppression and Plant Growth Promotion
}

\author{
Alberto Pascale ${ }^{1 \dagger}$, Silvia Proietti ${ }^{2 \dagger}$, lakovos S. Pantelides ${ }^{3 *}$ and loannis A. Stringlis ${ }^{4 *}$ \\ ${ }^{1}$ Department of Agricultural Sciences, University of Naples Federico II, Naples, Italy, ${ }^{2}$ Department of Ecological and \\ Biological Sciences, University of Tuscia, Viterbo, Italy, ${ }^{3}$ Department of Agricultural Sciences, Biotechnology and Food \\ Science, Cyprus University of Technology, Limassol, Cyprus, ${ }^{4}$ Plant-Microbe Interactions, Department of Biology, \\ Science4Life, Utrecht University, Utrecht, Netherlands
}

OPEN ACCESS

Edited by: Paulo José Pereira Lima Teixeira, University of São Paulo, Brazil

Reviewed by: Ka Wai Ma, Max Planck Institute for Plant Breeding Research, Germany Kei Hiruma,

Nara Institute of Science and Technology (NAIST), Japan

*Correspondence:

lakovos S. Pantelides

iakovos.pantelides@cut.ac.cy

loannis A. Stringlis

I.Stringlis@uu.nI

${ }^{\dagger}$ These authors share first authorship

Specialty section: This article was submitted to Plant Microbe Interactions,

a section of the journal Frontiers in Plant Science

Received: 30 September 2019 Accepted: 11 December 2019

Published: 24 January 2020

Citation:

Pascale A, Proietti S, Pantelides IS and Stringlis IA (2020) Modulation of the Root Microbiome by Plant Molecules: The Basis for Targeted Disease Suppression and Plant Growth Promotion.

Front. Plant Sci. 10:1741. doi: 10.3389/fpls.2019.01741
Plants host a mesmerizing diversity of microbes inside and around their roots, known as the microbiome. The microbiome is composed mostly of fungi, bacteria, oomycetes, and archaea that can be either pathogenic or beneficial for plant health and fitness. To grow healthy, plants need to surveil soil niches around the roots for the detection of pathogenic microbes, and in parallel maximize the services of beneficial microbes in nutrients uptake and growth promotion. Plants employ a palette of mechanisms to modulate their microbiome including structural modifications, the exudation of secondary metabolites and the coordinated action of different defence responses. Here, we review the current understanding on the composition and activity of the root microbiome and how different plant molecules can shape the structure of the root-associated microbial communities. Examples are given on interactions that occur in the rhizosphere between plants and soilborne fungi. We also present some well-established examples of microbiome harnessing to highlight how plants can maximize their fitness by selecting their microbiome. Understanding how plants manipulate their microbiome can aid in the design of next-generation microbial inoculants for targeted disease suppression and enhanced plant growth.

Keywords: plant defense, plant growth promotion, plant molecules, root exudation, root microbiome, microbiota, disease suppression, microbial inoculants

\section{INTRODUCTION}

Plants are sessile organisms anchored in the soil by their roots. In terrestrial ecosystems, plants are the main food producers supporting most of the other life. In nature, plants are continuously exposed to various biotic stresses caused by pathogens or pests and adverse environmental conditions, such as drought, soil salinity, extreme temperatures, nutrient deficiencies, or exposure to heavy metals (De Coninck et al., 2015; Antoniou et al., 2017; Hacquard et al., 2017). To survive biotic stresses, plants have evolved an array of sophisticated immune responses which protect plant cells from the challenges they confront (Pieterse et al., 2012; Pieterse et al., 2014). For decades, the interactions between plants and pathogens were studied under the prism of an 
individual plant-microbe relationship, ignoring the complexity of such interactions and the involvement of many other groups of microorganisms that affect the outcome of infection (Mendes et al., 2011; Berendsen et al., 2012; Bulgarelli et al., 2013). Over the last years, focus has been diverted to the effect of the plantassociated microbial communities on plant growth and health. Increasing evidence suggests that services provided by plantassociated microorganisms can broaden immune functions of the plant host (Vannier et al., 2019). It has even been postulated that plants actively recruit soil microorganisms by releasing compounds in the rhizosphere that selectively stimulate microorganisms that are beneficial to plant growth and health (Reinhold-Hurek et al., 2015; Sasse et al., 2017). Here, we review the current understanding on the composition and activity of the root-associated microbial communities, and we discuss how different plant molecules can shape the structure of these communities providing also with examples on the interactions between plants and soilborne fungi.

\section{Plants and Microbiome Game of Biomes: Plants Roots and Their Microbiome}

Plants harbor a mesmerizing diversity of microbes both in their aboveground and their belowground tissues that are collectively known as plant microbiota, while the genomes of the microbiota living in close association with plants are commonly referred to as the plant microbiome (Berendsen et al., 2012; Bulgarelli et al., 2013). This review will focus on the interactions of the microbiome with the root, which is the plant organ "hidden" in the soil that mediates key functions for plant longevity and fitness (De Coninck et al., 2015). Some of these functions are the fixation of a plant in a position, the uptake and storage of nutrients and water from the soil and the mediation of the interaction with soil-inhabiting microbes (Figure 1). Roots and their surrounding soil constitute one of the most rich and diverse ecosystems on Earth. The grand concentration of microbial life in the thin soil layer surrounding the roots, known as the rhizosphere, is explained by the release of carbon-rich products of photosynthesis which are a vital food source for the attracted microbes (Bais et al., 2006; Sasse et al., 2017). Rhizodeposits are quite diverse and include organic acids, amino acids, sugars, products of secondary metabolism, and even the release of dying root cap border cells (Dakora and Phillips, 2002; Bais et al., 2006; Driouich et al., 2013). Root-derived exudates, apart from supporting microbial proliferation in the rhizosphere, are also responsible for the formation of distinct microbial assemblages between soil and the rhizosphere, a phenomenon described as the "rhizosphere effect" (Hiltner, 1904; Berendsen et al., 2012). The microbes proliferating in the rhizosphere are therefore exposed to plant-derived compounds and signaling molecules
A

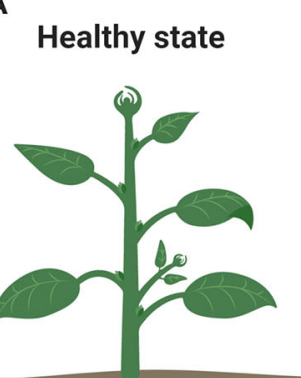

B

\section{Infection}

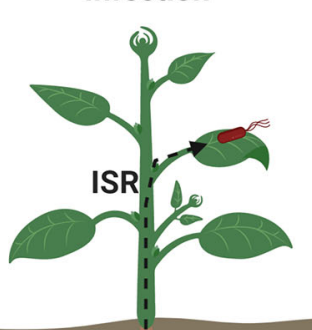

C

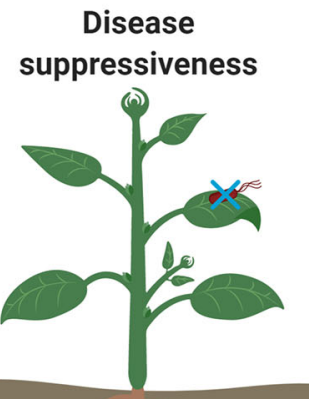

D Nutrient Deficiency

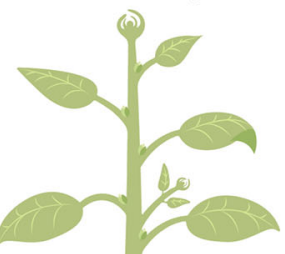

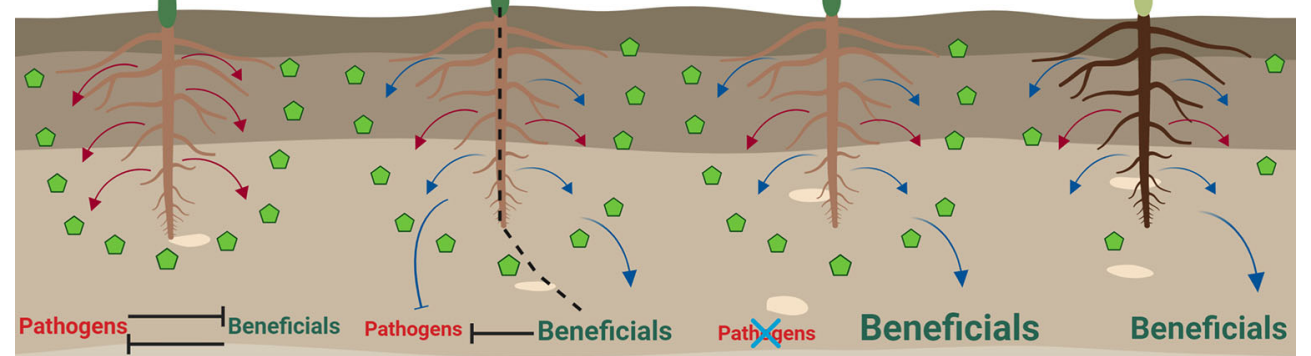

FIGURE 1 | Plants respond to different environmental stresses and modulate their microbiome. (A) Plants not experiencing any biotic stress and having access to nutrients (green pentagons), release constitutively exudates (red arrows) that allow them to sustain a balance in the rhizosphere between pathogenic and beneficial microbes. (B) Upon infection by a pathogen (red microbe), the exudation profile of roots changes and stress-induced exudates (blue arrows) aid the plants in inhibiting pathogenic growth in the rhizosphere, while selecting at the same time for beneficial microbes. Some of these beneficial microbes when they establish themselves in the rhizosphere, can trigger ISR that can help plants deal with pathogenic infections in the leaves. (C) In the case of soil suppressiveness or "cry-forhelp" conditions, there is establishment of beneficial rhizosphere communities that are further supported by the release of stress-induced exudates. Under these conditions, soilborne and foliar pathogens fail to cause disease. (D) Plants experiencing nutrient deficiencies (e.g. iron, nitrogen, phosphate) change the metabolomic profile of their roots to either make nutrients more available and soluble or to attract beneficial microbes (e.g. rhizobia, AMF, PGPR) that can help them deal with the nutrient deficiency. Font size indicates the abundance of beneficial or pathogenic subsets of the microbiota under different conditions. The figure was designed with Biorender (https://biorender.com). 
and represent a subset of the highly complex microbial communities of the bulk soil (Berendsen et al., 2012). A next layer of selection occurs when microbes grow on the root surface (rhizoplane) or inside roots (endosphere) and in turn less diverse microbial communities are observed (Bulgarelli et al., 2013; Reinhold-Hurek et al., 2015; Hacquard et al., 2017). These layers of selection are critical considering that the rootassociated microbiota consist of microbes that can assist plants in nutrient assimilation, or enhance their growth and defense potential, but also of microbes that can be detrimental for plant health (Lugtenberg and Kamilova, 2009; Pieterse et al., 2014; De Coninck et al., 2015). Therefore, the maintenance of a balance between plant health and the accommodation of this plethora of microbes in the root rhizosphere requires a coordination of complex processes in the rhizosphere where all partners benefit (Zamioudis and Pieterse, 2012).

\section{The Identity of Root-Associated Microbiomes}

The last decade several studies unearthed the composition of root-associated microbial communities. Most of these studies employed next-generation sequencing of microbial marker genes like $16 \mathrm{~S}$ rRNA for bacteria and the nuclear ribosomal internal transcribed spacer (ITS) region for fungi (Claesson et al., 2010; Schoch et al., 2012) which is known as amplicon sequencing (Sharpton, 2014), while others used shotgun metagenomics sequencing where not only selected microbial marker genes but all DNA present in an environmental sample is sequenced (Sessitsch et al., 2012; Ofek-Lalzar et al., 2014; Bai et al., 2015; Bulgarelli et al., 2015; Stringlis et al., 2018b). The latter approach allows not only for the taxonomic profiling of the root-associated microbial communities but also for the functional characterization of the microbiome (Sharpton, 2014). These culture-independent methodologies allowed the characterization of the microbiota in both the rhizosphere but also in the endosphere of different plant species. In the case of bacteria, analysis at phylum level revealed that the microbiota of healthy Arabidopsis thaliana (hereafter Arabidopsis) plants originates from the more diverse soil communities, and is dominated by the phyla Proteobacteria, Actinobacteria, Bacteroidetes and less by Firmicutes (Bulgarelli et al., 2012; Lundberg et al., 2012). Similarly, the root microbiome of closely related species belonging to the Brassicaceae family (Cardamine hirsuta, Arabidopsis halleri, Arabidopsis lyrata and Arabis alpina) display quite similar root microbial assemblages with those of Arabidopsis (Schlaeppi et al., 2014; Dombrowski et al., 2017). In plant species not related to Arabidopsis, such as barley, citrus, rice, Lotus japonicus, poplar, sugarcane, and tomato, the phyla Proteobacteria, Actinobacteria, Bacteroidetes, and Firmicutes constitute the highest proportion among the identified bacteria (Bulgarelli et al., 2015; Edwards et al., 2015; De Souza et al., 2016; Zgadzaj et al., 2016; Beckers et al., 2017; Zhang et al., 2017; Kwak et al., 2018). For fungal communities, studies in Arabidopsis, Arabis alpina, poplar, and sugarcane have shown that mostly the phyla Ascomycota, Basidiomycota and less Zygomycota, and Glomeromycota dominate the root microbiota of their host plants (Shakya et al., 2013; De Souza et al., 2016; Almario et al., 2017; Robbins et al., 2018; Bergelson et al., 2019). The high representation of selected bacterial and fungal phyla in roots and rhizospheres of different hosts suggests that members of these phyla constitute competitive and adaptable colonizers under various soil types and locations (Muller et al., 2016). Indeed, sequencing of microbiome DNA and RNA from the rhizosphere and the root of Brassica napus and citrus demonstrated that phyla Proteobacteria, Actinobacteria, Acidobacteria and Bacteroidetes are really active in the root and the rhizosphere and assimilate most of the carbon released by the roots (Gkarmiri et al., 2017; Zhang et al., 2017). Metatranscriptomics, functional studies or labelling of carbon absorption revealed that overrepresentation of specific fungal phyla in the rhizosphere correlates with their increased activity around the roots or services they provide to the host plants (Vandenkoornhuyse et al., 2007; Turner et al., 2013; Almario et al., 2017; Gonzalez et al., 2018).

\section{Interactions of Plants With Beneficial and Pathogenic Microbes}

Beneficial Associations With Plants

Symbiotic Plant-Microbe Associations. Research has unearthed that intimate interactions of plants with beneficial microbes first occurred millions of years ago. The first land plants were colonized by ancestral filamentous fungi that facilitated water absorption and nutrient acquisition for the host plant, while fungi received back photosynthetically-fixed carbon (Field et al., 2015; Martin et al., 2017). This symbiotic association coevolved in such a successful direction since more than $90 \%$ of living plant species form symbioses with mycorrhizal fungi, of which about $80 \%$ are classified as arbuscular mycorrhizal fungi (AMF) (Parniske, 2008; Bonfante and Genre, 2010). As obligate biotrophs, AMF need to sense the presence of the host plants to complete their lifecycle. The root-exuded plant hormone strigolactone has been recognized as the stimulatory signal for AMF mycelium metabolism and branching and its concentration gradient from the roots reveal the proximity to the host plant (Parniske, 2008; Bonfante and Genre, 2010). Intriguingly, AMF signaling pathways are very similar to the one that coordinates the well-known symbiosis between the paraphyletic group of rhizobial bacteria and leguminous plants and are therefore named common signaling symbiotic pathways (CSSPs) (Maclean et al., 2017; Martin et al., 2017). In rhizobia, the symbiotic association begins with the perception of specific root-exuded iso-flavonoid compounds by the microbes that stimulates root nodule formation (Begum et al., 2001; Oldroyd, 2013; Poole et al., 2018). Once symbiosis is established there is continuous exchange of nutrients between the host plant and the microbes. AMF can uptake the consistently low water-soluble inorganic orthophosphate $(\mathrm{Pi})$ from soils and transport $\mathrm{Pi}$ through the extraradical mycelium network and fungal arbuscules inside the root. AMF can also uptake and transport other major nutrients; for example nitrogen is transferred in the forms of nitrate, ammonium, and amino acids inside plants by using specialized transporters (Parniske, 2008; Bonfante and Genre, 2010; Maclean et al., 2017). In exchange, AMF receive the entire carbon 
requirements from plants, through specific fungal hexose transporters and fatty acids (Jiang et al., 2017; Maclean et al., 2017). In rhizobia-leguminous plants symbiosis, rhizobia reduce atmospheric $\mathrm{N}_{2}$ to ammonia inside the root nodules and secrete it to plants, while plants provide rhizobia with dicarboxylates (Poole et al., 2018).

Nutrient Uptake and Growth Promotion by Beneficial Microbes. Plants can acquire nutrients even in the absence of symbiosis with AMF or rhizobia. Enhanced nutrient acquisition in plants is a very common mechanism of phytostimulation (Lugtenberg and Kamilova, 2009; Finkel et al., 2017; Jacoby et al., 2017; Verbon et al., 2017) and a wide array of microbes can accomplish this function in non-mycorrhizal plants (Almario et al., 2017; Castrillo et al., 2017; Fabianska et al., 2019). The nonhost plant Arabidopsis acquires Pi through its natural root endophytic symbiont Colletotrichum tofieldiae (Hiruma et al., 2016). Hiruma and colleagues (2016) demonstrated that Pi translocation is the main plant growth promotion mechanism provided by $C$. tofieldiae and this mechanism is governed by the plant phosphate starvation status and requires intact immune system of the plant. Endophytic fungi belonging to the order of Sebacinales, such as Serendipita indica (formerly known as Piriformospora indica) can also promote plant growth through Pi acquisition (Yadav et al., 2010; Weiss et al., 2016). Similarly, Trichoderma fungi can produce chelating metabolites that solubilize phosphate and increase its acquisition by plants to promote plant growth (Altomare et al., 1999; De Jaeger et al., 2011). Nitrogen acquisition is mediated on non-leguminous plants by other microbes which are not belonging in the $\mathrm{N}$-fixing bacteria group (Jacoby et al., 2017; Martin et al., 2017). Evidence also accumulates that during root colonization selected beneficial microbes can hijack the iron deficiency response of plants. In this case, following bacterial colonization there is induction of the expression of genes with a role in iron uptake, and these genes are commonly used by plants to mobilize and uptake iron, when this element is present in unavailable forms in the soil (Zamioudis et al., 2015; Zhou et al., 2016; Martinez-Medina et al., 2017; Verbon et al., 2017).

Beneficial microbes can promote plant growth by affecting the hormonal balance of plants. This beneficial effect can be induced by the secretion of microbial small secondary metabolites (SM) that can act as hormone-like plant growth regulators, or by the production of SM and proteins that enable microbes to modulate the signaling of plant defense hormones to successfully colonize plant tissues (Verbon and Liberman, 2016; Patkar and Naqvi, 2017; Manganiello et al., 2018; Stringlis et al., 2018c). Numerous microbial species among plant associated bacteria and fungi can produce indole-3-acetic acid (IAA) or auxin-mimicking molecules that play a direct role on plant growth and development (Duca et al., 2014; Garnica-Vergara et al., 2016). Other microbial phytohormones or phytohormone-like molecules, such as cytokinins, gibberellins and analogues of defense-related hormones, such as salicylic acid (SA) or jasmonic acid (JA)-isoleucine are mainly produced to facilitate microbial colonization through modulation of plant immunity (Schafer et al., 2009; Stringlis et al., 2018c). Moreover, many plant beneficial microorganisms produce 1-aminocyclopropane1-carboxylate (ACC) deaminase that cleaves ACC, the immediate biosynthetic precursor of ethylene (ET) in plants, and promote plant growth presumably by lowering plant ET which can reach inhibitory levels for plant growth when subjected to stress conditions (Viterbo et al., 2010; Brotman et al., 2013; Glick, 2014; Stringlis et al., 2018c).

Induced Systemic Resistance. Another well-studied mechanism of elevated plant defense potential is the so-called induced systemic resistance (ISR) which is triggered by beneficial members of the root microbiome to a wide range of plant hosts making them resistant against various pathogenic threats (Pieterse et al., 2014). Systemic activation of plant defenses is ensured by a complex network of defense-related hormone signaling pathways, which brings the message of a beneficial interaction, in different plants organs (Pieterse et al., 2009; Pieterse et al., 2014). The ISR phenomenon has been firstly described for bacteria of the genus Pseudomonas, and this mechanism has been distinguished from "systemic acquired resistance" (SAR) which is induced by pathogens (Pieterse et al., 2014). ISR has also been described for many plant growth-promoting bacteria (PGPR) of the genus Bacillus and Serratia and plant growth-promoting fungi (PGPF) of the genus Trichoderma, Fusarium, Serendipita and AMF (Harman et al., 2004; Kloepper et al., 2004; Shoresh et al., 2010; Jung et al., 2012; Pieterse et al., 2014) and is determined by the perception of microbial secreted SM (Ongena and Jacques, 2008; Raaijmakers et al., 2010; Manganiello et al., 2018; Stringlis et al., 2018c). Interestingly, ISR is characterized by the activation of defense responses only after pathogen attack, saving the plant from a great energy consumption. This mechanism of "upon attack" defense activation is known as priming and is an energy-saving evolutionary strategy that allows plants to silently alert their immune system until a challenge by pathogens or insects occurs. Following this challenge, plants will deploy all the cellular responses faster and/or stronger resulting in a more efficient and effective resistance (Pieterse et al., 2014; Martinez-Medina et al., 2016).

All the beneficial associations presented above are based on the interaction between the host plant and a single beneficial microbe. Modern holistic approaches aim to correlate plant health to the entire plant-associated microbial community. In this case, microbial genes are considered as an extension of the plant genetic repertoire and perform specific functions benefiting plant growth, reproduction and disease resistance (Vandenkoornhuyse et al., 2015; Hassani et al., 2018). Community level-based metagenomic studies can elucidate whether there is functional redundancy or overlapping genomic traits in most microbes promoting plant growth or inducing systemic resistance, enabling in this way the discovery of novel PGPR or PGPF (Lugtenberg and Kamilova, 2009; Pieterse et al., 2014; Bai et al., 2015; Zeilinger et al., 2016; Berendsen et al., 2018; Duran et al., 2018).

\section{Plant-Pathogen Interactions}

During plant life, roots support beneficial associations with soilinhabiting microbes but need to cope at the same time with the 
infections caused by pathogenic microorganisms. Soilborne pathogens can affect hundreds of plant species, including economically important crops, and cause significant monetary losses due to significant reduction in yield and quality. For many crops, losses are estimated at $10 \%-20 \%$ of the attainable yield (Pimentel et al., 1991; Okubara and Paulitz, 2005; De Coninck et al., 2015). However, crop losses are often underestimated as soilborne pathogens are not an immediate concern for growers and their practices in many cases lead to increased inoculum reservoirs in soils (Chellemi et al., 2016). Also, their economic importance is expected to significantly rise due to the increasing implementation of conservation tillage or no-till farming practices in many countries (De Coninck et al., 2015) and the climate change that can increase their geographical range on Earth (Cheng et al., 2019). Soilborne pathogens reside in the soil for short or extended periods, and survive as saprophytes on plant residues and organic matter or as resting structures (e.g. sclerotia, chlamydospores, oospores, melanized mycelia) until triggered to grow by root exudates (Bruehl, 1987; Bais et al., 2006; De Coninck et al., 2015). For example, phenolic acids, sugars, and free amino acids in root exudates from watermelon significantly increased spore germination and sporulation of $F$. oxysporum f. sp. niveum (Hao et al., 2010). Similarly, tomato root exudates stimulated microconidia germination of the tomato pathogens F. oxysporum f. sp. lycopersici and F. oxysporum f. sp. radicis-lycopersici and the level of stimulation was affected by plant age (Steinkellner et al., 2005). Moreover, root exudates can be detected by fungal pathogens enabling fungal hyphae to orient their growth towards the root. For example, the chemotropic response of $F$. oxysporum towards tomato roots was recently characterized and involves the catalytic activity of root-secreted class III peroxidases (Turrà et al., 2015). Under favorable environmental conditions, soilborne pathogens invade plants through the root system and in most cases roots and other belowground parts are directly affected; however, symptoms are often visible on above ground parts of plants (Koike et al., 2003). Plants infected by soilborne pathogens suffer from root rots, inhibition of root development, stunted growth, seedling damping-off, stem and collar rots, wilting or even plant death (De Coninck et al., 2015; Katan, 2017). Diseases caused by soilborne plant pathogens are notoriously difficult to control for several reasons: many soilborne pathogens produce persistent resting structures that can survive in the soil for many years even in the absence of a susceptible host (Katan, 2017); measures targeting resting structures (e.g. chemical fumigation) are unsuitable for large-scale application due to public health and environmental issues and ban on chemical fumigants (Yadeta and Thomma, 2013); application of pesticides is often insufficient because of the poor accessibility in soil matrix (De Coninck et al., 2015); some of the soilborne pathogens infect a wide range of host plants rendering cultural control measures ineffective (Antoniou et al., 2017). Moreover, in order to establish a parasitic relationship with the plants, pathogens must interact with the complex rhizosphere community that also influences the outcome of the infection (Raaijmakers et al., 2009). Pathogens are negatively affected by co-inhabiting microorganisms through antibiosis and competition for nutrients, processes that usually involve secreted molecules. Snelders et al. (2018) proposed that pathogens can fight back by delivering effector proteins which target the rhizosphere communities instead of the plant to ultimately facilitate host colonization by the pathogen. Soilborne pathogens include species of fungi, oomycetes, bacteria, viruses and nematodes (Katan, 2017). The most important soilborne fungal pathogens are Fusarium oxysporum (Michielse and Rep, 2009), Fusarium solani (Coleman, 2016), Rhizoctonia solani (Gonzalez et al., 2011), Verticillium spp. (Klosterman et al., 2009), and Sclerotinia sclerotiorum (Bolton et al., 2006) and destructive soilborne oomycetes are Phytophthora spp. (Van West et al., 2003; Lamour et al., 2012) and Pythium spp. (Van West et al., 2003). Among many soil bacteria that are beneficial, there are only a few groups that infect the plant roots. Examples are Ralstonia solanacearum (Peeters et al., 2013) and the causal agent of crown gall Agrobacterium tumefaciens (Anand et al., 2008) that require a natural opening or wound to penetrate into the plant and cause infection. Only a small number of viruses can infect roots and like bacteria, they require an opening to achieve penetration. They generally survive only in the living tissues of the host plant or in their vectors. In soil, viruses are transmitted by zoosporic fungi (Campbell, 1996) or by nematodes (Brown et al., 1995).

\section{How Do Plants Select Microbes and Defend Against Pathogens Effect of Root Exudates on Root-Associated Microbiome}

Plants produce and exude via their roots various metabolites that can affect the assembly of the root microbiome before even microbes reach the root surface where they confront with the plant immune system (Sasse et al., 2017). The age and developmental stage of the plant influence exudation and subsequently the microbes proliferating around roots. Exudates of Arabidopsis plants collected at different plant age varied in sugar levels which affected accordingly microbial functions related with sugar and secondary metabolism (Chaparro et al., 2013). It was also shown that Arabidopsis plants during the early and late stage of their development can influence the abundance of Actinobacteria, Bacteroidetes and Cyanobacteria and microbial activity as well (Chaparro et al., 2014). Functions aligning with pathogens were more represented at early developmental stages while later developmental stages were dominated by functions related with antibiosis and chemotaxis and aligned to beneficial microbes, suggesting a selective pressure during plant aging towards microbes that provide their hosts with important services. In this direction, a recent study elegantly demonstrated that exudates change during the growth cycle of Avena barbata with sucrose levels are high at earlier stages while amino acids and defense molecules are released more at later developmental stages (Zhalnina et al., 2018). Using exometabolomics, this study showed that selected metabolites including aromatic organic acids (nicotinic, shikimic, salicylic, 
cinnamic, and IAA) are responsible for the proliferation or not of specific microbes around the roots during the different growth stages of the host plant (Zhalnina et al., 2018).

Different rhizodeposits have been shown to influence the microbiome composition. Studies on how plants select rootassociated microbes/microbiota are summarized in Table $\mathbf{1}$. Biosynthesis of aliphatic and indolic glucosinolates, that are components of the chemical defense of plants, occurs in the vascular stele (Xu et al., 2017). Early studies demonstrated that root exudation of aliphatic glucosinolates can affect the rhizospheric microbial communities (Bressan et al., 2009), while indolic glucosinolates accumulate in Arabidopsis root upon pathogen infection (Bednarek et al., 2005). Combinations of exudates collected from Arabidopsis plants growing in vitro and applied in soil in the absence of plants revealed differential effects of phenolic compounds on the abundance of bacterial taxa (Badri et al., 2013). More specifically, phenolics seemed to have the biggest effect on the growth and attraction of bacterial operational taxonomic units (OTUs), followed by amino acids and sugars. A role of phenolics in affecting soil microbial diversity was also demonstrated with an Arabidopsis $A B C$ transporter mutant ( $a b c g 30)$ which releases more phenolics but shows a reduced export of sugars (Badri et al., 2009). In soil in which abcg30 plants were grown, an increased abundance of PGPR or bacteria involved in heavy metal remediation was observed compared to wild type Col-0 plants, suggesting a role for phenolics in attracting beneficial microbes. More recent studies suggested that coumarins, which are also phenolic compounds, can shape the rhizosphere microbiome and display differential toxicity against beneficial and pathogenic microbes (Stringlis et al., 2018b; Stringlis et al., 2019a; Voges et al., 2019). Next to phenolics, more chemical players have been found to contribute in the balance between roots and the microbiome, including benzoxazinoids ( $\mathrm{Hu}$ et al., 2018; Cotton et al., 2019), triterpenes (Huang et al., 2019), and camalexin (Koprivova et al., 2019). Other naturally occurring exudates, like flavonoids and strigolactones, act as signaling compounds for the establishment of well-characterized symbiotic interactions of plant hosts with rhizobia and AMF (Akiyama et al., 2005; Subramanian et al., 2007). Moreover, border cells and borderlike cells that are forming an extra root layer between the root tip and soil have been shown to affect a group of soilborne bacteria, because of proteins synthesized and released through them (Driouich et al., 2013). Arabinogalactan proteins were identified among the secreted molecules and were found to regulate Rhizobium and Agrobacterium attachment on roots (Gaspar et al., 2004; Vicre et al., 2005; Xie et al., 2012). Different parts of the root can release a different blend of exudates that can favor the colonization by selected members of the microbiome (Baetz and Martinoia, 2014). Studies using modern techniques like microfluidics and bacterial biosensors responsive to selected root exudates have revealed the preferential colonization of the root elongation zone and of lateral roots by bacteria of the genera Bacillus and Rhizobium (Massalha et al., 2017; Pini et al., 2017).

\section{Structural Root Defenses and Microbiome}

Plants have developed various ways to restrict microbial growth and colonization on plant tissues, once microbes overcome niche competition with other microbes in the rhizosphere and can successfully grow in root exudates. In leaves, an armory of structural and chemical defense mechanisms have evolved to prevent disease caused by colonization of harmful microbes inside plant tissues (Senthil-Kumar and Mysore, 2013). These structural defense components include the cuticle, lignin, suberin and deposition of callose and are also present in the roots. Roots are plant organs characterized by radial organization where each concentric layer corresponds to a different tissue (Wachsman et al., 2015). Lignin fortifies the xylem of Arabidopsis roots (Van De Mortel et al., 2008; Naseer et al., 2012) and going outwards from the root core, lignin-composed Casparian strips (CS) and the hydrophobic polymer suberin make the endodermis a barrier between the xylem and the soil (Naseer et al., 2012; Geldner, 2013). Recognition of microbes or of microbial elicitors can induce callose deposition in the epidermal cells of the root (Millet et al., 2010; Jacobs et al., 2011; Hiruma et al., 2016). Finally, cutin as a waxy polymer of the cuticle coating the epidermis, has barrier-like properties like suberin and is present in the primary and lateral roots (Berhin et al., 2019). Evidence suggests that plant defense components exert some selective pressure on the microbes that can colonize the inner tissues of the root. The first seminal studies on the root microbiome field demonstrated that the endosphere microbiota is a fraction of the rhizosphere microbiota, and structural defense components might have a role in this observation (Bulgarelli et al., 2012; Lundberg et al., 2012). Other structural modifications of the root system like emergence of lateral roots or formation of root hairs might be involved in creating micro-niches that host distinct subsets of the root microbiota. A study in barley comparing wild type and mutant plants for root hair formation revealed that the microbial community in root hair mutants was simpler and less diverse compared to the microbial communities assembled in the roots of wild type barley plants (Robertson-Albertyn et al., 2017). Despite the presence of structural defense components in roots and their dynamic contribution in plant growth, information on their role in the assembly of the root microbiome is still limited.

\section{Interplay Between Plant Immunity and the Microbiome}

\section{Root Immune System}

As already mentioned in this review, soil microbial populations consist of a mix of beneficial and pathogenic microbes. Hence, plants need to successfully recognize them and subsequently reprogram their defense strategies to allow or block their colonization (Zamioudis and Pieterse, 2012; Yu et al., 2019a). To effectively and timely perceive microbial signals, plants have evolved a multilayered detection system that leads, depending on the trigger, to the activation of downstream defense responses (Dodds and Rathjen, 2010). In the first layer of this defense system, surface-localized pattern recognition receptors (PRRs) 
TABLE 1 | Representative studies where plants under different stresses can select/modulate the assembly of the root-associated microbiome. For each study (when possible) the trigger leading to plant activity that modulates the microbiome, the identified mechanism of action, the effect on the microbiome, the host plant and the reference is mentioned.

\begin{tabular}{|c|c|c|c|c|}
\hline Trigger & Mechanisms & Effect & Host & Reference \\
\hline \multicolumn{5}{|l|}{ Pathogen-triggered } \\
\hline $\begin{array}{l}\text { Fusarium oxysporum } \\
\text { f. sp. lycopersici }\end{array}$ & Disease -induced recruitment from suppressive compost & $\begin{array}{l}\text { Enrichment of Proteobacteria, Actinobacteria, and } \\
\text { Firmicutes (Bacillus) }\end{array}$ & Tomato & $\begin{array}{l}\text { Antoniou } \\
\text { et al., } 2017\end{array}$ \\
\hline $\begin{array}{l}\text { Hyaloperonospora } \\
\text { arabidopsidis/ } \\
\text { Pseudomonas } \\
\text { syringae pv. tomato }\end{array}$ & Legacy-mediated development of soil suppressiveness & Assemblage of beneficial rhizosphere microbiome & $\begin{array}{l}\text { Arabidopsis/ } \\
\text { Tomato }\end{array}$ & $\begin{array}{l}\text { Berendsen } \\
\text { et al., 2018/ } \\
\text { Yuan et al., } \\
2018\end{array}$ \\
\hline Rhizoctonia solani & $\begin{array}{l}\text { Activation of bacterial stress responses and activation of } \\
\text { antagonistic traits that restrict pathogen infection }\end{array}$ & $\begin{array}{l}\text { Shifts in microbiome composition and enrichment of } \\
\text { Oxalobacteraceae, Burkholderiaceae, } \\
\text { Sphingobacteriaceae, and Sphingomonadaceae }\end{array}$ & Sugar beet & $\begin{array}{l}\text { Chapelle } \\
\text { et al., } 2016\end{array}$ \\
\hline Botrytis cinerea & $\begin{array}{l}\text { Chemoattraction induced by root-exuded peroxidases } \\
\text { and oxylipins }\end{array}$ & $\begin{array}{l}\text { Attraction of Trichoderma harzianum and inhibition } \\
\text { of Fusarium oxysporum }\end{array}$ & $\begin{array}{l}\text { Tomato; } \\
\text { Cucumber }\end{array}$ & $\begin{array}{l}\text { Lombardi } \\
\text { et al., } 2018\end{array}$ \\
\hline Rhizoctonia solani & Pathogen-induced taxa enrichment from suppressive soils & $\begin{array}{l}\text { Recruitment of specific taxa from rhizosphere of } \\
\text { sugar beet infected with Rhizoctonia solani }\end{array}$ & Sugar beet & $\begin{array}{l}\text { Mendes et al., } \\
2011\end{array}$ \\
\hline $\begin{array}{l}\text { Pseudomonas } \\
\text { syringae pv. tomato }\end{array}$ & Root-secreted malic acid & Recruitment of Bacillus subtilis FB17 & Arabidopsis & $\begin{array}{l}\text { Rudrappa } \\
\text { et al., } 2008\end{array}$ \\
\hline $\begin{array}{l}\text { Fusarium oxysporum } \\
\text { f. sp. lini }\end{array}$ & $\begin{array}{l}\text { Disease-induced recruitment of beneficial microbes from } \\
\text { Fusarium suppressive soils }\end{array}$ & $\begin{array}{l}\text { Increase of taxa associated to Fusarium wilt } \\
\text { suppressiveness }\end{array}$ & Flax & $\begin{array}{l}\text { Siegel-Hertz } \\
\text { et al., } 2018\end{array}$ \\
\hline $\begin{array}{l}\text { Huanglongbing (HLB) } \\
\text { caused by Candidatus } \\
\text { Liberibacter spp. } \\
\text { Insects-triggered }\end{array}$ & $\begin{array}{l}\text { Putative mechanisms: HLB significantly altered the } \\
\text { structure or functional potential of the citrus endosphere }\end{array}$ & $\begin{array}{l}\text { Decrease in abundance of taxa and loss of functions } \\
\text { in the rhizoplane-rhizosphere enriched microbiome } \\
\text { of HLB- infected citrus roots }\end{array}$ & Citrus & $\begin{array}{l}\text { Zhang et al., } \\
2017\end{array}$ \\
\hline Aphids & $\begin{array}{l}\text { Elicitation of plant immunity via SAJA systemic signaling } \\
\text { and expression of pathogenesis-related (PR) proteins in } \\
\text { roots }\end{array}$ & $\begin{array}{l}\text { Recruitment of the beneficial bacteria Bacillus } \\
\text { subtilis and decrease of the population of Ralstonia } \\
\text { solanacearum }\end{array}$ & Pepper & $\begin{array}{l}\text { Lee et al., } \\
2012\end{array}$ \\
\hline Whitefly & $\begin{array}{l}\text { Whitefly infestation elicited SA and JA signaling in above } \\
\text { and below ground tissues and overexpression of PR } \\
\text { genes in the roots resulting in a differential microbiome } \\
\text { assembly }\end{array}$ & $\begin{array}{l}\text { The differential microbiome assembly induced } \\
\text { resistance against to Xanthomonas axonopodis pv. } \\
\text { vesicatoria and Ralstonia solanacearum }\end{array}$ & Pepper & $\begin{array}{l}\text { Yang et al., } \\
2011\end{array}$ \\
\hline
\end{tabular}

\section{Abiotic stress/nutrient deficiency-triggered}

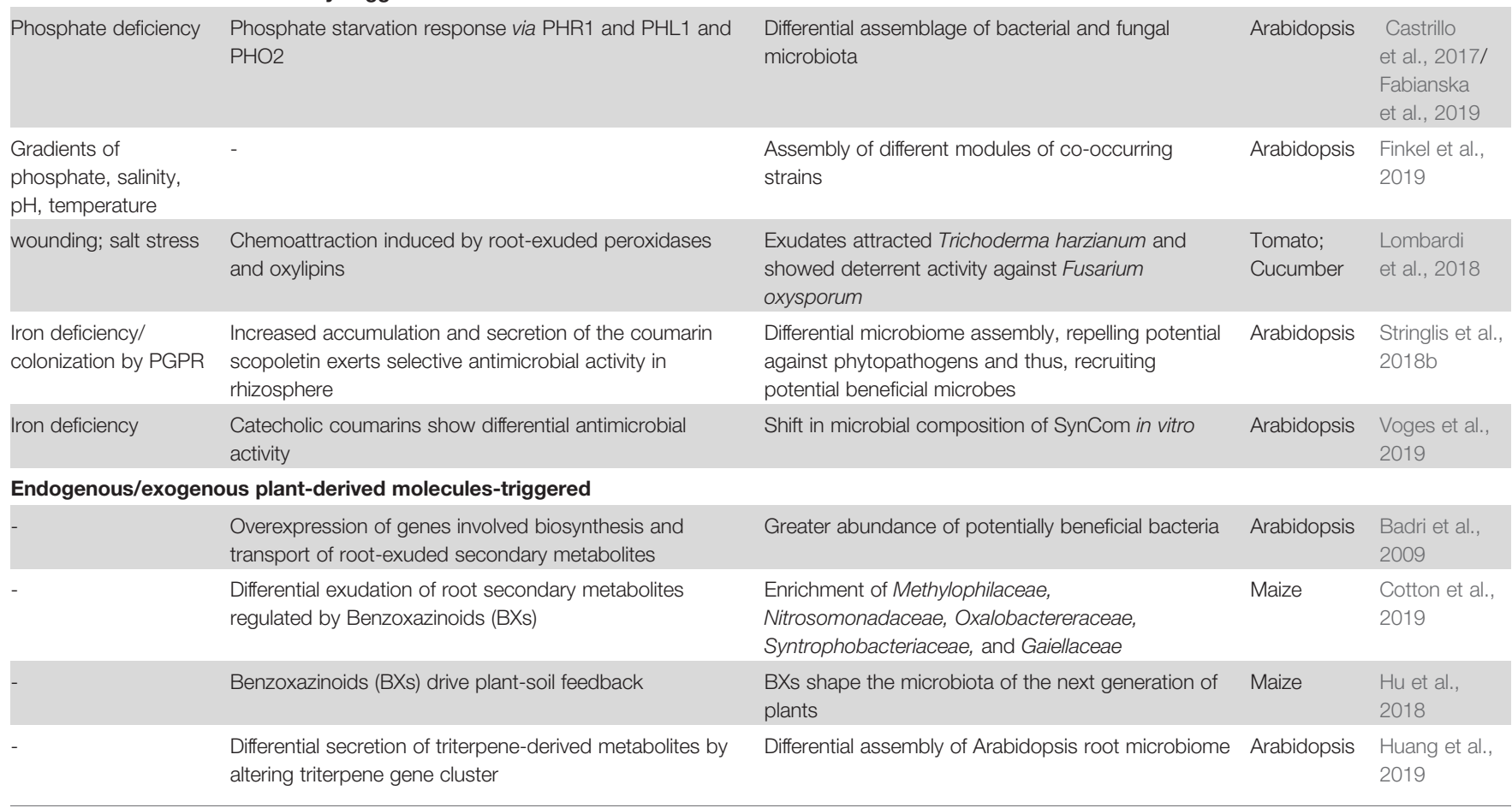

(Continued) 
TABLE 1 | Continued

\begin{tabular}{|c|c|c|c|c|}
\hline Trigger & Mechanisms & Effect & Host & Reference \\
\hline \multicolumn{5}{|c|}{ Pathogen-triggered } \\
\hline- & $\begin{array}{l}\text { Microbial sulfatase cleaves root-exuded sulfate esters } \\
\text { produced by the camalexin biosynthetic pathway }\end{array}$ & $\begin{array}{l}\text { Stimulation of microbial sulfatase activity in soil and } \\
\text { is required for the plant growth-promoting effects of } \\
\text { several bacterial strains }\end{array}$ & Arabidopsis & $\begin{array}{l}\text { Koprivova } \\
\text { et al., } 2019\end{array}$ \\
\hline- & $\begin{array}{l}\text { Assembly of differential microbiome between tomato } \\
\text { cultivars susceptible and resistant to Ralstonia } \\
\text { solanacearum }\end{array}$ & $\begin{array}{l}\text { Enrichment of Flavobacterium in the microbiome of } \\
\text { tomato cultivars resistant to Ralstonia, } \\
\text { Flavobacterium application confers resistance to } \\
\text { susceptible cultivar }\end{array}$ & Tomato & $\begin{array}{l}\text { Kwak et al., } \\
2018\end{array}$ \\
\hline SA & $\begin{array}{l}\text { Compromised innate immune system impairing SA } \\
\text { biosynthetic pathway }\end{array}$ & $\begin{array}{l}\text { SA-dependent modulation of root microbiome and } \\
\text { enrichment of Flavobacterium, Terracoccus, and } \\
\text { Streptomyces in SA-treated roots and bulk soils }\end{array}$ & Arabidopsis & $\begin{array}{l}\text { Lebeis et al., } \\
2015\end{array}$ \\
\hline- & $\begin{array}{l}\text { DIMBOA Benzoxazinoids (BXs) induce chemotaxis- } \\
\text { associated genes in Pseudomonas putida }\end{array}$ & Enhanced rhizosphere colonization by $P$. putida & Maize & $\begin{array}{l}\text { Neal et al., } \\
2012\end{array}$ \\
\hline $\mathrm{ACC} ; \mathrm{JA}$ & $\begin{array}{l}\text { ACC and JA application, induced altered expression of } \\
\text { PRR and RLK and cell wall biosynthesis and maintenance } \\
\text { related genes }\end{array}$ & $\begin{array}{l}\text { Inhibition of the secondary stage of root colonization } \\
\text { by Laccaria bicolor }\end{array}$ & Poplar & $\begin{array}{l}\text { Plett et al., } \\
2014 b\end{array}$ \\
\hline
\end{tabular}

perceive conserved microbe-derived molecules, called microbeassociated molecular patterns (MAMPs). In Arabidopsis, some MAMP/PRR pairs are well defined (Couto and Zipfel, 2016). Bacterial flagellin and the immunogenic epitope of flagellin flg22 are perceived by receptor kinase FLAGELLIN-SENSING 2 (FLS2) (Gomez-Gomez and Boller, 2000), while ELONGATION FACTOR-TU RECEPTOR (EFR) recognizes bacterial elongation factor $\mathrm{Tu}$ and its derived immunogenic peptide elf18 (Kunze et al., 2004). Additionally, CHITIN ELICITOR RECEPTOR KINASE 1 (CERK1) and LYSIN MOTIF CONTAINING RECEPTOR-LIKE KINASE 5 (LYK5) recognize hepta- or octamers of the fungal elicitor chitin (Miya et al., 2007; Cao et al., 2014). The recognition of a MAMP leads to the induction of immune responses in the host plant that constitute the first layer of defense referred to as MAMPtriggered immunity (MTI). Based on their timing, the activated immune responses range from instant [medium alkalization, oxidative burst (ROS), protein phosphorylation] and early (ethylene biosynthesis, defense gene activation) to late (callose deposition and growth inhibition) (Boller and Felix, 2009). All these processes aim to halt any further growth of a microbe on/in plant tissues and have been elucidated by the extensive study of pathogen perception in the aerial plant tissues. During the last decade, many studies have shown that roots can perceive MAMPs and generate MAMP-specific responses such as callose deposition, camalexin biosynthesis, and induction of defence-related genes similar to leaves (Millet et al., 2010; Jacobs et al., 2011; Wyrsch et al., 2015; Poncini et al., 2017; Stringlis et al., 2018a; Marhavy et al., 2019). Constitutive activation of PRRs in microbe- and elicitor-enriched environments like roots and the surrounding rhizosphere could result in unnecessary MTI that in turn could cause growth and yield inhibition of plants (Gomez-Gomez et al., 1999; Vos et al., 2013). For this, different researchers aimed to define the involvement of different plant organs in flg22 perception by its receptor FLS2 (Beck et al., 2014) and the contribution of different root tissues in the induction of MTI upon flg22 elicitation (Wyrsch et al., 2015). Interestingly, inner tissues show higher expression of the FLS2 receptor and stronger MAMP responses (ROS production and induction of defense genes) compared to epidermal tissues. However, it's not only the plant side that adapts to the presence of MAMPs, but the microbes themselves adapt to the presence of PRRs. Only a small fraction of the genomes of the culturable microbiome of Arabidopsis (3\%-6\%) contains genes coding for flg22 or elf18 peptides, while the peptide cold shock protein 22 (csp22) recognized by Solanaceae and not by Arabidopsis is present in $25 \%$ of the isolated Arabidopsis-associated microbes (Wang et al., 2016; Hacquard et al., 2017). This suggests that the presence of PRRs in roots exerts a selective pressure on the root-associated microbes that need to develop mechanisms to mask the presence of their MAMPs and achieve colonization. Some PRRs can also identify "self" molecules known as hostderived damage-associated molecular patterns (DAMPs). In response to cellular rupture by nematodes or fungal attack, DAMPs are released and can induce strong tissue specific responses in the roots of Arabidopsis (Poncini et al., 2017; Marhavy et al., 2019). Considering the potential of DAMPs to induce stronger defense responses in the roots compared to MAMPs (Poncini et al., 2017), their role in the assembly of the root microbiome and on how plants discriminate between beneficial and pathogenic root colonizers should be expected.

Suppression of Root Defenses by Beneficial Microbes. Signaling pathways of defense hormones SA and JA have been longinvolved in responses of plants to infection by pathogens or colonization by beneficial microbes (Pieterse et al., 2012; Zamioudis and Pieterse, 2012; Pieterse et al., 2014) and studies using mutants for these hormonal pathways have demonstrated their role in shaping the root microbiome (Carvalhais et al., 2015; Lebeis et al., 2015). Beneficial members of the root microbiota have developed different strategies to suppress MTI and/or manipulate the homeostasis of defense hormones to achieve colonization and provide their host with benefits (Zamioudis and Pieterse, 2012; Yu et al., 2019a). Symbiotic mycorrhizal and ectomycorrhizal fungi Rhizophagus irregularis and Laccaria bicolor secrete mutualism 
effectors that manipulate ET and JA hormonal signaling pathways (Kloppholz et al., 2011; Plett et al., 2011; Plett et al., 2014a; Plett et al., 2014b), while effectors of endophytic fungus Serendipita indica target JA signaling to achieve defense suppression (Jacobs et al., 2011; Akum et al., 2015). JA signaling is also upregulated by PGPF Trichoderma spp. to suppress activation of immune responses during early colonization of the root (Brotman et al., 2013). Beneficial bacteria employ different strategies to manipulate the host and accomplish colonization. The type III secretion system (T3SS) is important in the establishment of symbiosis between rhizobia and their legume partners (Zamioudis and Pieterse, 2012). T3SS is a multicomponent apparatus that Gram negative bacteria, mostly pathogenic, use to secrete effector molecules into host cells aiming to restrict the defense responses mounted due to their recognition and achieve host colonization (Galan and Collmer, 1999). Sinorhizobium fredii HH103 with defective T3SS is unable to suppress SA-dependent defenses and subsequently fails to promote nodulation on its legume host (Jimenez-Guerrero et al., 2015). Non-symbiotic PGPR such as Pseudomonas fluorescens SBW25, Pseudomonas brassicacearum Q8r1-96 and Pseudomonas simiae WCS417 and other root-associated Pseudomonads, are also equipped with T3SS, however its role in root colonization remains elusive (Preston et al., 2001; Mavrodi et al., 2011; Loper et al., 2012; Berendsen et al., 2015; Stringlis et al., 2019b). Nevertheless, beneficial microbes can employ other mechanisms independent of secretion systems to mask their presence in the rhizosphere. Pathogenic bacteria Pseudomonas aeruginosa and Pseudomonas syringae release the extracellular alkaline protease AprA which degrades flagellin monomers, and allows microbes to have their MAMPs undetected by the immune system of both mammals and plants (Bardoel et al., 2011; Pel et al., 2014). Plant-beneficial bacteria have AprA homologs in their genomes so a role of this protease in their interaction with roots is possible (Pel et al., 2014). More recently, Yu et al. (2019b) suggested another mode of plant manipulation where beneficial rhizobacteria of the genus Pseudomonas spp. produce organic acids during root colonization that lower the environmental $\mathrm{pH}$ and in turn suppress root immune responses following recognition of the flg22 peptide.

\section{Phenomena Where Selection Occurs Building Up of Disease Suppressiveness}

Soil microbial communities provide silently their valuable services in terrestrial ecosystems by increasing ecosystem resilience, making soil more resistant to any disturbance-induced damages due to environmental changes (Berendsen et al., 2012). Disease suppression is a well-known microbiome-mediated phenomenon that provides a first line of defense against infections by the soilborne pathogens (Weller et al., 2002). Disease suppressive soils have been originally defined as "soils in which the pathogen does not establish or persist, establishes but causes little or no damage, or establishes and causes disease for a while but thereafter the disease is less important, although the pathogen may persist in the soils" (Baker and Cook, 1974). In contrast, in conducive soils the disease occurs readily. Two types of soil suppressiveness have been characterized: "general" and "specific" suppression. In general suppression, growth and activity of pathogens are inhibited to some extent and the suppressiveness is attributed to the antagonistic activity of the collective microbial community that is often associated with competition for available resources (Mazzola, 2002; Weller et al., 2002; Cook, 2014). General suppressiveness is enhanced by the incorporation of organic amendments or other management practices that increase the total microbial activity and competition in the soil (Weller et al., 2002; Bonanomi et al., 2010). It is often effective against a broad range of pathogens and is not transferable between soils (Cook and Rovira, 1976; Weller et al., 2002). General suppressiveness is a pre-existing characteristic of soils and is fundamentally microbiological in nature (Weller et al., 2002; Raaijmakers and Mazzola, 2016). Specific suppression occurs when individual species or specific subsets of soil microorganisms interfere with the infection cycle of a pathogen (Weller et al., 2002; Berendsen et al., 2012). The biotic nature of specific suppression is also demonstrated as it can be eliminated through soil pasteurization or biocides. In contrast to general suppressiveness, specific suppressiveness can be transferred by introducing very small amounts $(1 \%-10 \%)$ of suppressive soil into a conducive soil (Cook and Rovira, 1976; Mendes et al., 2011; Raaijmakers and Mazzola, 2016; Schlatter et al., 2017). Specific suppression is superimposed over the general suppression and is more effective (Berendsen et al., 2012). In some soils specific suppression is retained for prolonged periods even when soils are left bare, whereas in other soils it is induced by continuous monoculture of a susceptible host after a disease outbreak (Berendsen et al., 2012; Raaijmakers and Mazzola, 2016). Induction of specific suppression requires multilateral interactions between plants, soil microbiome and pathogens and is mechanistically complex. The interaction between plant and pathogen that occurs before a disease outbreak may induce the release of pathogen- or plantderived metabolites that lead to alterations in microbiota composition and activation of pathogen-suppressive microorganisms (Chapelle et al., 2016). In recent years, many studies using new culture-independent technologies started to unravel the identity of responsible microorganisms in disease suppressive soils (Gomez Exposito et al., 2017). For instance, suppressiveness towards Verticillium dahliae was mainly associated with higher abundances of Actinobacteria and Oxalobacteraceae (Cretoiu et al., 2013). Another study regarding fungi revealed significant differences in the fungal community composition between suppressive and non-suppressive soil for the disease caused by R. solani AG 8; Xylaria, Bionectria, and Eutypa were more abundant in the suppressive soil whereas Alternaria and Davidiella dominated the non-suppressive soil (Penton et al., 2014). Also, higher abundances of the Phyla Actinobacteria, Proteobacteria, Acidobacteria, Gemmatimonadetes, and Nitrospirae were found in soil with specific suppressiveness to Fusarium wilt of strawberry (Cha et al., 2016). More recently, it was shown that fungal and bacterial diversity differed significantly between a suppressive and a conducive soil of Fusarium wilt whereas several of the fungal and bacterial genera known for their activity against $F$. oxysporum were detected exclusively or more abundantly in the Fusarium wilt-suppressive soil (Siegel-Hertz 
et al., 2018). Interestingly, studies analyzing the rhizobacterial community composition in soils suppressive or conducive to $R$. solani revealed that relative abundance of specific bacterial taxa is a more important indicator of suppressiveness than the exclusive presence or absence of specific bacterial families (Mendes et al., 2011; Chapelle et al., 2016). In a study by Hu et al. (2016) defined Pseudomonas species consortia were introduced into naturally complex microbial communities to assess the importance of the Pseudomonas community diversity for the suppression of $R$. solanacearum in the tomato rhizosphere. Only the most dense and diverse Pseudomonas communities reduced pathogen density in the rhizosphere and decreased the disease incidence due to both intensified resource competition and interference with the pathogen. Recently, Wei et al. (2019) demonstrated that the composition and functioning of the initial soil microbiome predetermines future disease outcome of $R$. solanacearum on tomato plants. Plant survival was associated with specific bacterial species, including the highly antagonistic Pseudomonas and Bacillus bacteria together with specific rare taxa. The mechanism behind the suppression could be the production of antibiotics, as high abundance of genes encoding non-ribosomal peptide and polyketide synthases was found in the initial microbiomes associated with healthy plants. Intriguingly, they also demonstrated that this capacity can be transferred to the next generation of plants through soil transplantation opening a new avenue of exploiting microbiomes for disease resistance.

\section{Microbiome Modulation by Coumarins, Benzoxazinoids, and Other Root-Exuded Molecules Coumarins}

Coumarins are phenolic compounds produced via the phenylpropanoid pathway and have been extensively studied for their role in disease resistance (Stringlis et al., 2019a) but also for their involvement in responses of dicotyledonous plants to iron deficiency (Tsai and Schmidt, 2017a). Coumarins are produced when iron is unavailable in the soil around the roots and their exudation increases to make iron more available before it is imported inside the roots (Tsai and Schmidt, 2017b; Tsai and Schmidt, 2017a). Coumarins with pronounced production/ exudation in response to iron deficiency are scopolin, scopoletin, esculin, esculetin, fraxetin and sideretin (Jin et al., 2007; Rodriguez-Celma et al., 2013; Fourcroy et al., 2014; Schmid et al., 2014; Schmidt et al., 2014; Fourcroy et al., 2016; Rajniak et al., 2018; Tsai et al., 2018). Recent studies have suggested their role also in shaping microbiome composition around the roots (Stringlis et al., 2018b; Voges et al., 2019). Stringlis et al. (2018b) showed that both under iron deficiency and colonization of roots by beneficial rhizobacteria that induce ISR, there is increased accumulation of coumarins inside the roots. Components of the production and exudation of coumarins in this study were genes with a key role in ISR, such as the root-specific transcription factor MYB72 and beta-glucosidase gene BGLU42 (Verhagen et al., 2004; Van Der Ent et al., 2008; Zamioudis et al., 2014; Stringlis et al., 2018b). More specifically, in myb72 mutant plants no coumarin accumulation was observed inside the roots, while in bglu42 mutant plants there was reduced exudation of coumarin scopoletin. Analysis of the rhizosphere microbiomes in these mutants plants, the coumarin biosynthesis mutant $f 6^{\prime} h 1$ (Kai et al., 2008; Schmid et al., 2014) and wild-type plants revealed that coumarins can affect the composition of the microbiome around the roots (Stringlis et al., 2018b). There was increase in the relative abundance of Proteobacteria but decrease of Firmicutes in the $f 6^{\prime} h 1$ rhizosphere compared to wild-type plants rhizosphere. Further experiments showed that coumarin scopoletin was inhibiting the growth of soilborne pathogens whereas rhizobacteria that induce ISR were insensitive to its antimicrobial activity (Stringlis et al., 2018b; Stringlis et al., 2019a). Voges et al. (2019) showed that coumarins can shape the composition of a synthetic bacterial community inoculated in in vitro grown plants and there was enrichment of a Pseudomonas strain in $f 6^{\prime} h 1$ compared to wild-types plants growing under iron deficiency. In this study, it was suggested that the antimicrobial effect of catecholic coumarins fraxetin and sideretin, produced downstream of scopoletin (Rajniak et al., 2018; Tsai et al., 2018), are due to the hydrogen peroxide deriving from catecholic coumarins at conditions of iron deficiency (Voges et al., 2019).

\section{Benzoxazinoids}

Benzoxazinoids are a class of compounds, quite abundant in the roots of maize, with a documented role in the attraction of beneficial microbes in the rhizosphere (Neal et al., 2012) and the defense responses of plants to various pathogenic threats (Ahmad et al., 2011). Recently, studies have focused on characterizing how benzoxazinoids can shape the assembly of root-associated bacterial and fungal communities (Hu et al., 2018; Cotton et al., 2019). Hu et al. (2018) using a benzoxazinoids deficient maize mutant observed that different bacterial and fungal communities assemble in the roots of the mutants compared to wild-type maize. Despite the prominent changes in bacterial and fungal microbiome the authors didn't assess the effects of benzoxazinoids on specific bacterial/fungal taxa. Release of benzoxazinoids and the subsequent microbiome changes were sufficient to provide plants of a next generation growing in this soil with protection against a herbivore insect. Next-generation maize plants growing in soil with and without benzoxazinoids displayed distinct bacterial and fungal communities both in the root and the rhizosphere. Actinobacteria OTUs and some Ascomycota and Glomeromycota OTUs were mostly responsible for root and rhizosphere separation but the effects on plant fitness were more strongly associated with changes in bacteria than fungi in the rhizosphere of these next-generation plants (Hu et al., 2018). There was increase of a subset of Proteobacteria in soils with benzoxazinoids, while Chloroflexi OTUs were enriched in soils without benzoxazinoids. In the case of fungal communities, Ascomycota OTUs were present in both soils with and without benzoxazinoids. Interestingly, Glomeromycota OTUs seemed to be less abundant in soils with benzoxazinoids. In the study by Cotton et al. (2019), the effect of benzoxazinoids on the metabolomic profile of roots and microbiome assembly was assessed. Metabolomic profiles of mutants in benzoxazinoids production were different compared to those of wild type plants, indicating a role of benzoxazinoids in the metabolic response of maize roots. The microbiome analysis revealed enrichment or depletion of 
bacterial and fungal OTUs between the rhizospheres of wild type and mutant plants and the authors correlated the changes in the microbial abundance with metabolites present in the roots of wild type and mutant plants (Cotton et al., 2019). Studies like those presented herein on coumarins and benzoxazinoids enrich our understanding on how specific exudates shape root-associated microbial communities, and unlocking how a beneficial microbiome can be selected via exudation could allow us to breed for plants that can manipulate their microbiome to maximize growth and health benefits (Vannier et al., 2019).

\section{Triterpenes and Camalexin}

As already mentioned in section Effect of Root Exudates on RootAssociated Microbiome, triterpenes and camalexin were recently found to be involved in microbiome shaping (Huang et al., 2019; Koprivova et al., 2019). Triterpenes are products of plant metabolism with involvement in disease resistance and with antimicrobial activity (Papadopoulou et al., 1999). Triterpenes are synthesized via the mevalonate pathway and can accumulate in plant tissues as triterpene glycosides (Thimmappa et al., 2014). Huang et al. (2019) observed that triterpenes thalianin and arabidin are produced in roots and biosynthetic genes for their production are induced following treatment of roots with MeJA. Microbiome analysis of thalianin and arabidin mutants and wildtype plants revealed the assembly of distinct root microbial communities in the absence of triterpenes. These differences were explained by the enrichment of Bacteroidetes and the depletion of Deltaproteobacteria in the roots of triterpene mutants compared with the roots of wild type plants (Huang et al., 2019). In the study of Koprivova et al. (2019), the authors performed a genome wide association study (GWAS) and measured microbial sulfatase activity in the soil where 172 accessions of Arabidopsis were grown. Through this screen the authors found single-nucleotide polymorphisms (SNPs) explaining differences in microbial sulfatase activity. Some of these SNPs were in gene CYP71A27 and a mutant of this gene displayed reduced microbial sulfatase activity and impaired production of antimicrobial compound camalexin. Interestingly, the authors observed that beneficial rhizobacteria could promote growth in wild-type plants but only beneficial rhizobacteria without sulfatase activity could promote growth in cyp71a27 mutants. The fact that beneficial rhizobacterium Pseudomonas sp. CH267 could promote growth in wild-type plants but not in nine Arabidopsis accessions with variation in the amino acid sequence of CYP71A27, suggested that camalexin is required in the interaction of roots with microbes in order the plants to have a benefit (Koprivova et al., 2019).

\section{"Cry for Help" During Infection of Plants}

Plants experiencing infection by phytopathogens or insects, actively recruit beneficial members from the rhizosphere microbiota that will help them overcome biotic stresses, a phenomenon defined as "cry for help" (Bakker et al., 2018). Studies have shown that the build-up of a beneficial microbial community in the root is mediated by changes in gene expression and alterations in root exudation responsive to pathogen attack (Figure 1). Rudrappa et al. (2008) showed that infection of
Arabidopsis leaves by Pseudomonas syringae pv. tomato (Pst) induced the root exudation of malic acid that in turn favored the recruitment of the beneficial Bacillus subtilis strain FB17 which triggers ISR in Arabidopsis against Pst. Tomato plants experiencing different stresses produced exudates that acted as chemoattractants for the beneficial fungus Trichoderma harzianum (Lombardi et al., 2018). Other studies have shown that aphid feeding or whitefly infestation of pepper and tobacco leaves can cause a transcriptional reprogramming in roots and changes in the root microbiome composition which makes plants more resistant to foliar and soilborne pathogens (Yang et al., 2011; Lee et al., 2012; Lee et al., 2018). Recently, Berendsen et al. (2018) demonstrated that Arabidopsis leaf infection by the biotrophic oomycete Hyaloperonospora arabidopsidis (Hpa) can lead to the enrichment of three bacterial taxa (Xanthomonas spp., Stenotrophomonas spp., and Microbacterium spp.) in the rhizosphere. Isolation of these microbes and inoculation of Arabidopsis showed that these three microbes together could induce ISR against Hpa and promote plant growth, indicating the active recruitment of beneficial microbes by infected plants. Microbiome changes were also apparent in Arabidopsis infected with Pseudomonas syringae and those changes were attributed to changes in root exudation (Yuan et al., 2018). In these studies, the beneficial effect in plant health due to microbiome changes could be transferred to the offspring of the infected plants that displayed increased levels of resistance to these pathogens (Berendsen et al., 2018; Yuan et al., 2018). These findings indicate that in soils with infected plants changes in exudation and the microbiome lead to the build-up of a microbial legacy that is inherited to the next generations of plants growing in this soil and favors their survival under phytopathogenic pressure (Bakker et al., 2018). Considering the continuity of plantpathogens interactions during the lifetime of a plant in a field, a functional "loop" should be in action: when plants experience stress they respond with changes in exudation that can favor the selection of beneficial microbial members from the rhizosphere which in turn can help the plants deal with the stress (Liu et al., 2019a). Future studies should elucidate how different exudates contribute in the microbial recruitment and the subsequent soilborne legacy described above, considering the involvement of coumarins (Stringlis et al., 2018b; Stringlis et al., 2019a), malic acid (Rudrappa et al., 2008), benzoxazinoids (Hu et al., 2018; Cotton et al., 2019), and camalexin (Koprivova et al., 2019) in the selection of beneficial microbes in the rhizosphere.

\section{Rhizosphere Microbiome as a Source of Benefits for the Plant \\ Beneficial Effects Against Biotic Stresses}

It is well documented that plant genotype exerts strong influence on the overall composition of root associated communities through plant root exudates (Bulgarelli et al., 2012; Badri et al., 2013; Matthews et al., 2019). Recent evidence suggest that root exudates attract beneficial and pathogen-suppressing microbes or reshape microbiome assembly in the plant rhizosphere to suppress disease symptoms (Kwak et al., 2018; Mendes et al., 2018). The study of Mendes et al. (2018) using common bean 
cultivars with variable levels of resistance has shown that rhizobacteria belonging to Pseudomonadaceae, Bacillaceae, Solibacteraceae, and Cytophagaceae families were more abundant in the rhizosphere of the Fusarium-resistant cultivar. Kwak et al. (2018) analyzed the rhizosphere microbiomes of a resistant and a susceptible tomato variety to the soilborne pathogen $R$. solanacearum to assess the role of plant-associated microorganisms in disease resistance and proved that transplantation of rhizosphere microbiota from resistant plants suppressed disease symptoms in susceptible plants. By comparing the metagenomes of the rhizosphere from resistant and susceptible plants a flavobacterial genome was identified to be far more abundant in the resistant plant rhizosphere. The isolated flavobacterium could suppress $R$. solanacearum in pot experiments with a susceptible tomato variety suggesting that selection of native microbiota can protect plants from root pathogens. Recently, it was shown that in natural populations of Arabidopsis, the plants are protected against root-inhabiting filamentous eukaryotes because of the presence of the co-residing bacterial root microbiota that is essential for plant survival (Duran et al., 2018). In another microbiome study, the occurrence of potato common scab caused by Streptomyces was correlated with the composition and putative function of the soil microbiome (Shi et al., 2019). The community composition of the geocaulosphere soil samples revealed that Geobacillus, Curtobacterium, and unclassified Geodermatophilaceae were the most abundant genera that were significantly negatively correlated with the scab severity level, the estimated absolute abundance of pathogenic Streptomyces, and $t x t A B$ gene copy number (biosynthetic gene of the scab phytotoxin). In contrast, Variovorax, Stenotrophomonas, and Agrobacterium were the most abundant genera that were positively correlated with these three parameters.

Direct pathogen suppression by rhizospheric microorganisms has been extensively reported (Mendes et al., 2011; Santhanam et al., 2015; Cha et al., 2016; Hu et al., 2016). Pathogen growth is affected by several and highly diverse mechanisms including microbial competition (for resources or space) (Zelezniak et al., 2015), secretion of antimicrobial compounds (Chen et al., 2018; Helfrich et al., 2018; Stringlis et al., 2018b; Koprivova et al., 2019) and hyperparasitism (Parratt and Laine, 2018). As mentioned previously, members of the rhizosphere microbiome can alter plant growth by producing phytohormones which modulate endogenous plant hormone levels (Stringlis et al., 2018c). In a recent study, two synthetic microbial communities were designed and consisted of bacterial strains that show ACC deaminase activity and produce an array of hormones and enzymes in vitro and also show antimicrobial activity against F. oxysporum f. sp. lycopersici. Inoculation of these synthetic communities in a poor substrate enhanced the growth of tomato plants and reduced symptoms caused by $F$. oxysporum f. sp. lycopersici (Tsolakidou et al., 2019a). In another study, endophytic Enterobacteriaceae strains engineered to express ACC deaminase activity on the bacterial cell walls did not show any activity against a pathogenic strain of Fusarium oxysporum f. sp. cubense in vitro. However, they promoted banana plant growth and increased resistance to banana Fusarium wilt suggesting that engineering the interactions between plants with their microbiome can provide valuable tools to deal with plant pathogens that are difficult to control (Liu et al., 2019b). Pathogenic microbes can employ similar strategies with beneficial microbes to colonize their hosts. For example, overexpression of ACC deaminase gene in $V$. dahliae significantly lowered ACC levels in the roots of infected tomato plants and increased both its virulence and the fungal biomass in the vascular tissues of plants (Tsolakidou et al., 2019b). Therefore, future studies need to address how functions shared by both beneficial and pathogenic microbes are perceived by the plants and how plants can maintain a balance in the rhizosphere.

\section{Beneficial Effects Against Abiotic Stresses}

Accumulating evidence suggests that the rhizosphere microbiome is not only involved in coping with biotic stresses but is also involved in protection of plants against abiotic stresses (Figure 1). Rhizosphere bacteria have been shown to elicit socalled induced systemic tolerance to high salinity, drought and nutrient deficiency or excess (Yang et al., 2009; Rolli et al., 2015). A recent study found a diverse range of root-associated bacteria of soybean and wheat, including Pseudomonas spp., Pantoea spp., and Paraburkholderia spp., showing mechanisms involved in improved nutrient uptake, growth, and stress tolerance like phosphate solubilization, nitrogen fixation, indole acetic acid and ACC deaminase production (Rascovan et al., 2016). Accumulation of heavy metals, hydrocarbons and pesticides in soil can cause deterioration of soil properties and have negative impact on plant growth or make the plant unsuitable for consumption (Kuiper et al., 2004). Interestingly, Sessitsch et al. (2012) found enrichment of microbial functions for the degradation of aromatic compounds in the metagenomes of endophytes, highlighting a potential for bioremediation. Understanding how microbiome dynamics and functions can change in response to perturbations can open new avenues to engineer microbial communities also for bioremediation purposes (Perez-Garcia et al., 2016; Eng and Borenstein, 2019). Indeed, soil tillage and compost amendment of contaminated soils could stimulate the indigenous microbial communities which are naturally adapted to the pollutants of these soils (Ventorino et al., 2019). In another study the modification of the microbiota assemblage following the introduction of a natural and diverse microbiome transplant in an oilcontaminated soil led to more efficient contaminant degradation compared to the introduction of an artificial microbial selection (Bell et al., 2016). Phytoremediation is the use of plants to extract, sequester, or detoxify pollutants. This practice is often associated with the microbial bioremediation since the presence of plants can stimulate the microbial population in the rhizosphere, improve physical and chemical properties of the soil and increase contacts between microbes and soil contaminants (Kuiper et al., 2004). In a recent work, Fan and colleagues found that inoculation of Robinia pseudoacacia with 
rhizobia, significantly affected rhizosphere microbial population and functions and also improved the phytoremediation capacity of the plants (Fan et al., 2018).

\section{Plant Microbiome as a Source of Variability in Plant Breeding}

The efforts of plant breeding practices have always been directed towards the selection of desirable phenotypic traits, such as higher yield associated with improved edible characteristics. This domestication process, progressively led to the loss of allelic diversity, also named as genetic erosion of domesticated plants (Perez-Jaramillo et al., 2016; Pieterse et al., 2016). Recent studies indicated that in several plant species the rhizosphere microbiome composition may have been affected in domesticated plants as compared to their wild relatives (PerezJaramillo et al., 2017; Perez-Jaramillo et al., 2018; Pérez-Jaramillo et al., 2019). For common bean, it was shown that relative abundance of Bacteroidetes was increased in wild accessions whereas Actinobacteria and Proteobacteria were enriched in modern accessions and this shifting was associated with plant genotypic and specific root morphological traits (Perez-Jaramillo et al., 2017). Interestingly, the transition of common bean from a native to an agricultural soil led to a gain of rhizobacterial diversity and to a stronger effect of the bean genotype on rhizobacterial assembly (Pérez-Jaramillo et al., 2019). In a study using 33 strains of sunflower (Helianthus annuus) with varying degrees of domestication it was found that rhizosphere fungal communities were more strongly influenced by host genetic factors and plant breeding than bacterial communities. They also found that there was a minimal vertical transmission of fungi from seeds to adult plants (Leff et al., 2017). A survey of the bacterial community structure of 3 barley accessions also pointed to a small but significant role of the host genotype on rootassociated community composition (Bulgarelli et al., 2015). Perez-Jaramillo et al. (2018) conducted a meta-analysis integrating metagenomics data of 6 independent studies with the aim of addressing whether plant domestication affected the composition of the root-associated microbiome in various crop plant species and observed consistent enrichment of Actinobacteria and Proteobacteria in modern varieties in contrast to the enrichment of Bacteroidetes in their wild relatives. This evidence indicates that modern agriculture may not utilize the full potential the associated microbiome may offer. In this framework, wild relatives have been suggested to provide new perspective into plant genes associated with microbiome assembly, and this knowledge could open new horizons for future breeding strategies (Perez-Jaramillo et al., 2018).

\section{Engineering Microbial Inoculants to Suppress Disease and Support Plant Growth: From the Lab to the Field The Prospect of Using Synthetic Communities to Promote Plant Health}

The successful application of microbial consortia as inoculants to protect plants from stresses and enhance their productivity relies mainly on the ability of microorganisms that show promise in the lab to overcome hurdles and retain their characteristics when applied in the field (Sessitsch et al., 2019). The rationale behind this strategy is twofold: the selection and combination i) of distantly related microorganisms with different or complementing characteristics tailored to promote plant growth and suppress pathogens, or tolerate different plant genotypes or environmental conditions (Compant et al., 2019), or ii) of closely related strains in order to expand the diversity of resources that these strains use (Wei et al., 2015; Hu et al., 2016). Species-rich communities are often more efficient and more productive than species-poor communities as they use limiting resources more efficiently (Loreau et al., 2001). For instance, the introduction of high diversity Pseudomonas consortia reduced $R$. solanacearum density in the rhizosphere of tomato plants and decreased the disease incidence due to interference and intensified resource competition with the pathogen. Interestingly, increasing diversity of the introduced Pseudomonas consortia also increased their survival ( $\mathrm{Hu}$ et al., 2016). Furthermore, increasing the richness of Pseudomonas consortia resulted in enhanced accumulation of plant biomass and more efficient assimilation of nutrients in tomato plants; diversity effects were more important than the identity of the Pseudomonas strain and the observed plant growth promotion was associated with elevated production of plant hormones, siderophores, and solubilization of phosphorus in vitro ( $\mathrm{Hu}$ et al., 2017). In contrast, increasing genotypic richness of $P$. fluorescens communities increased disproportionally the antagonistic interactions, causing community collapse and resulted in loss of Medicago sativa protection against the oomycete Pythium ultimum (Becker et al., 2012). It was recently proposed that microbial synthetic communities can be used as inoculants to produce plant growth substrates with desired characteristics such as biocontrol of targeted pathogens and plant growth promotion (Tsolakidou et al., 2019a). The composition of the synthetic communities was a determinant factor for the growth of plants and pathogen inhibition. The synthetic community consisting of different bacterial genera promoted the growth of tomato plants but failed to protect plants against Fusarium wilt. The synthetic community consisting of Bacillus isolates suppressed Fusarium wilt symptoms and enhanced tomato growth but to a lesser extent as compared to the more diverse synthetic community (Tsolakidou et al., 2019a).

There is a substantial number of studies suggesting that complex inocula can provide plants with increased disease resistance and growth promotion effects as compared to single strains (Rolli et al., 2015; Santhanam et al., 2015; Wei et al., 2015; Molina-Romero et al., 2017; Niu et al., 2017; Berendsen et al., 2018; Tsolakidou et al., 2019a). Bacterial strains that show little or no effects as single inoculants can exhibit plant growth promotion effects when used in a consortium (Raaijmakers and Weller, 1998; Berendsen et al., 2018).

The prospect of using microbial mixtures as plant inoculants that can positively affect plant properties is an emerging field of research (Figure 2). However, the complexity of experimentation is exponentially increasing when using synthetic microbial 


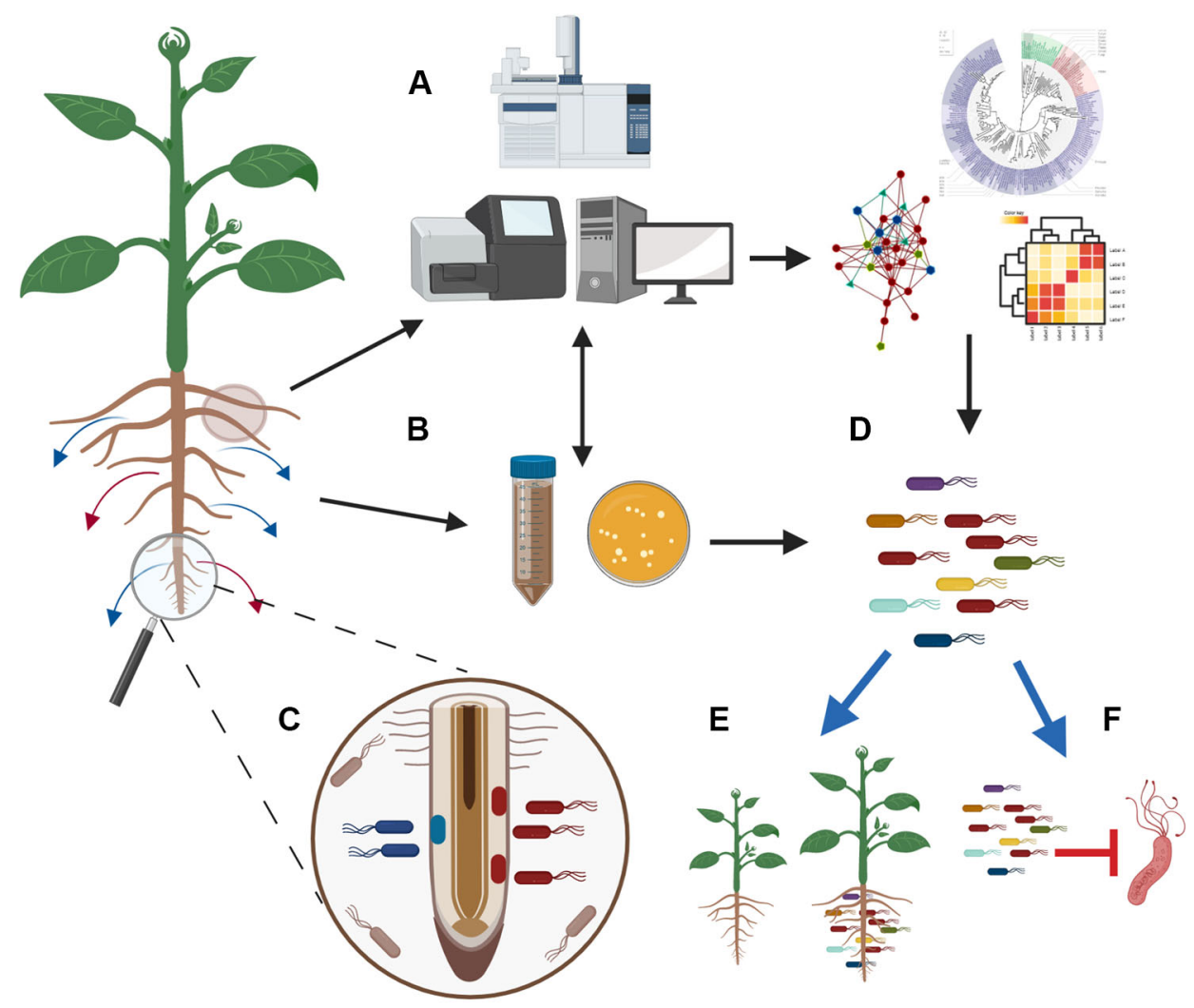

FIGURE 2 | Integration of modern technologies to engineer microbial inoculants that boost plant growth and suppress pathogens. Plants respond to stresses and change their exudation. To unravel how changes in exudation affect microbiome composition and functions, we need to couple advance metabolomic techniques with metagenomics sequencing (A) and culture-based methodologies (B). At the same time, there is promise for the use of exometabolomics methodologies and spatial metabolomics that can help in finding where specific exudates are produced and how the microbes around the exudation site are affected (C). Analysis of the generated data in depth will allow the characterization of the microbial communities that respond to exudates and the identification of networks that will reveal how microbes interact and contribute in the microbiome assembly (A). The parallel isolation of a representative fraction of the root microbiome (B) will allow to link descriptive data with the isolated microbes and will guide the design of synthetic communities (D). Testing of these synthetic communities with different hosts under different conditions (e.g. biotic/abiotic stress/in vitro/in soil/in field) will facilitate the selection of synthetic communities that can promote plant growth (E) and suppress pathogens (F) in a consistent and reproducible manner. The figure was designed with Biorender (https://biorender.com/).

communities as compared to single strain inoculants. Thus, successful implementation of microbial consortia with desired host outputs will depend on our understanding of how microorganisms interact with one another and with their hosts in natural ecosystems. To this direction, synthetic microbial communities have been widely adopted for fundamental discoveries in plant microbiomes research as a reductionist approach to simplify and especially control each component of this complex system (Bai et al., 2015; Lebeis et al., 2015; Finkel et al., 2019). Indeed, as cleverly postulated by Vorholt and colleagues (2017), the true strength of a synthetic community is that each member of the community can be singularly added or substituted, and this can be even accomplished at a functional level by silencing or expressing specific genes.

However, controlling each member of a large community would bring to a factorial number of possible combinations, making it impossible to control. Recently, Paredes and colleagues
(2018) developed a machine learning computational approach to design a bacterial synthetic community. This method was based on the "cry-for-help" theory, consisting in the construction of a neural-network model that received as inputs the growth rate of a pool of bacterial isolates grown with the root exudates of phosphate starved plants, and the phosphate content of shoots of plants in binary interaction with each one of these single bacterial isolates. This method allowed to design a synthetic community with consistent predictable plant phenotypes. In parallel, the construction of the synthetic community based on the "cry-forhelp" carried out by Berendsen and colleagues (2018) was more based on a plant-driven approach, where plants effectively attracted a consortium of beneficial bacteria which in turn produced desirable plant phenotypes. These examples show that the identification of microbes that mostly respond to plant stress signals can be used as reliable predictors for the discovery of beneficial microbes. 
Techniques and Workflows to Harness Plants and Engineer Beneficial Microbiomes

Engineering microbiomes to promote plant fitness and health is an emerging scientific field and an approach holding great promise towards the realization of sustainable future agriculture. However, there are many aspects and technical limitations that need to be considered to effectively exploit this technology. Here, we aim to summarize some of these considerations that are extensively discussed in a recent review by Lawson et al. (2019). First, to unravel mechanisms underlying the interactions between hosts and microbiomes, multiple omics techniques need to be integrated (Jansson and Baker, 2016). Metabolomics, metagenomics, plant transcriptomics, metatranscriptomics, and plant genetics are some of the approaches that combined can disentangle the complex interactions occurring between members of the holobiont. A thorough description of these methodologies are beyond the scope of this review, but some recent focused reviews are available for further reading (Van Dam and Bouwmeester, 2016; Levy et al., 2018; O' Banion et al., 2019; Rodriguez et al., 2019). Here, we report some examples where application of a multi-omics approach revealed how selected plant exudates produced under natural or under stress conditions can affect the colonization of roots by specific microbes. Hu et al. (2018) combined metabolomics and amplicon-based metagenomics analysis on two maize genotypes (wild type and a benzoxazinoids precursor mutant) and revealed how the defense-related benzoxazinoids metabolites structure the bacterial and fungal community of the maize rhizosphere. Stringlis et al. (2018b) also exploited the combination of shotgun metagenomics and metabolomics on an array of Arabidopsis mutants to demonstrate that root exudation of coumarins can shape the rhizosphere microbiome. Similarly, Huang et al. (2019) utilized metabolomics and metagenomics to reveal the effect that root-exuded triterpenes have on microbiota composition of the root. On the track of the work by Berendsen et al. (2018); Yuan et al. (2018) revealed the metabolic drivers of the "legacy effect" by combining metabolomics of the root exudates of infected plants with metagenomics analysis of the rhizospheres of these plants. Furthermore, in an elegant combination of exometabolomics, metagenomics and comparative genomics, Zhalnina et al. (2018) demonstrated how temporal dynamic exudation of root metabolites during different plant developmental stages assembled specific microbial communities and enriched for specific microbial functions. In a next step, we need to link how released plant molecules can affect microbial activity and unearth how plant secretions can define which root niches can be colonized by beneficial microbes while at the same time excluding the pathogenic ones (Jacoby and Kopriva, 2018; Levy et al., 2018).

Furthermore, as the blend of root exudates is strictly dependent on plant genotype, it is expectable that different plants attract different microbes that can produce similar effects on different hosts, due to the redundancy of functions of the microbiome. Considering this, we propose to use desirable microbiome functions as selective markers to identify potential beneficial microbes. By exposing different plant species to the same stress conditions, a comparative metatranscriptomics approach would allow the identification of common functions expressed by microbiomes upon the sensing of stress plant signals. Metatranscriptomics has already been used to highlight the most active members of microbiomes in different plant species or to identify bacterial genes expressed during different Arabidopsis life stages (Turner et al., 2013; Chaparro et al., 2014). To date, only a few metatranscriptomics studies have been conducted, due to the difficulties of mapping metatranscripts to reference genomes and metagenomes. Again, in this case, using synthetic communities composed of whole-genome sequenced members would facilitate this task. Associating these studies with detailed metabolomic analysis of root exudates from stressed plants would then make the integration of multi-omics techniques more and more reliable (Figure 2). All together these strategies would produce an incredible amount of data that still need to be interpreted. For this reason, it is necessary to develop bioinformatics techniques that would allow the reduction and summarization of these data. System biology approaches based on correlation networks have been proposed to discover microbial associations where positive and negative correlations can be used to infer possible synergistic or antagonistic interactions (Agler et al., 2016; Poudel et al., 2016; Van Der Heijden and Hartmann, 2016). With this methodology, it is also possible to identify the so-called microbial hub taxa which represent the most interactive nodes in the networks. In this direction, Agler et al. (2016) established a computational method which identified the plant pathogen Albugo and the fungus Dioszegia as microbial hubs in the microbiome of Arabidopsis phyllosphere. In a further experiment, through the artificial manipulation of the microbiome it was also demonstrated that the microbes identified as the hubs of the network, also represented "keystone taxa" as they drove the composition and function of the microbiome. The concept of "keystone" also has been adopted by Niu et al. (2017) when studying the contribution of individual members of a microbial synthetic community on the rhizosphere of maize plants. In this case, the removal of a singular member caused the collapse of the community functioning with the respective decrease of the richness indexes. These results clearly highlighted that some microbial individuals play a key role in shaping microbial communities on plant hosts.

Another very powerful computational approach is the use of metagenome-wide association study (MWAS). This method derives from the genome-wide association's studies, which rely on the construction of linear mixed models to relate genotypic variations to quantitative observed phenotypes. MWAS have been typically used in human metagenomics studies, i.e. to identify microbial taxa or microbial functions associated with a host phenotypic trait which could be a disease or the host metabolomics profile, by integrating a multi-omics approach (Gilbert et al., 2016). Genome-wide association approach has also been used in the study of plant-microbe interactions, i.e. to identify Arabidopsis loci associated with the ability of plants to maximize benefit from the interaction with the beneficial 
Pseudomonas strain WCS417 (Wintermans et al., 2016). In a plant-microbiome context, Beilsmith and colleagues (2019) propose to use MWAS to find associations between host genes and microbial taxa. MWAS could be very useful to find functional associations between either microbial genes and host genes, or microbial genes and host phenotype, which could also include root exudation profiles.

Finally, to build synthetic microbial communities with consistent beneficial effects for plants in the field, it is essential to understand whether a specific trait of a single strain is expressed in a community level and under multiple contexts (different environmental conditions, hosts, other microorganisms, etc.) (Vannier et al., 2019). This is crucial considering that single strains or synthetic communities that have beneficial effects in vitro and under controlled conditions might behave in a different manner in the field. We need also to be aware that the increasing complexity of the synthetic community decreases the feasibility of the large-scale industrial production of microbial inoculants. This should be considered in future plant-microbiome studies with a

\section{REFERENCES}

Agler, M. T., Ruhe, J., Kroll, S., Morhenn, C., Kim, S. T., Weigel, D., et al. (2016). Microbial hub taxa link host and abiotic factors to plant microbiome variation. PloS Biol. 14, e1002352. doi: 10.1371/journal.pbio.1002352

Ahmad, S., Veyrat, N., Gordon-Weeks, R., Zhang, Y., Martin, J., Smart, L., et al. (2011). Benzoxazinoid metabolites regulate innate immunity against aphids and fungi in maize. Plant Physiol. 157, 317-327. doi: 10.1104/pp.111.180224

Akiyama, K., Matsuzaki, K., and Hayashi, H. (2005). Plant sesquiterpenes induce hyphal branching in arbuscular mycorrhizal fungi. Nature 435, 824-827. doi: 10.1038/nature03608

Akum, F. N., Steinbrenner, J., Biedenkopf, D., Imani, J., and Kogel, K. H. (2015). The Piriformospora indica effector PIIN_08944 promotes the mutualistic Sebacinalean symbiosis. Front. Plant Sci. 6, 906. doi: 10.3389/ fpls.2015.00906

Almario, J., Jeena, G., Wunder, J., Langen, G., Zuccaro, A., Coupland, G., et al. (2017). Root-associated fungal microbiota of nonmycorrhizal Arabis alpina and its contribution to plant phosphorus nutrition. Proc. Natl. Acad. Sci. U. S. A. 114, 9403-9412. doi: 10.1073/pnas.1710455114

Altomare, C., Norvell, W. A., Bjorkman, T., and Harman, G. E. (1999). Solubilization of phosphates and micronutrients by the plant-growthpromoting and biocontrol fungus Trichoderma harzianum Rifai 1295-22. Appl. Environ. Microbiol. 65, 2926-2933. doi: 10.1128/aem.65.7.29262933.1999

Anand, A., Uppalapati, S. R., Ryu, C. M., Allen, S. N., Kang, L., Tang, Y., et al. (2008). Salicylic acid and systemic acquired resistance play a role in attenuating crown gall disease caused by Agrobacterium tumefaciens. Plant Physiol. 146, 703-715. doi: 10.1104/pp.107.111302

Antoniou, A., Tsolakidou, M. D., Stringlis, I. A., and Pantelides, I. S. (2017). Rhizosphere microbiome recruited from a suppressive compost improves plant fitness and increases protection against vascular wilt pathogens of tomato. Front. Plant Sci. 8, 2022. doi: 10.3389/fpls.2017.02022

Badri, D. V., Quintana, N., El Kassis, E. G., Kim, H. K., Choi, Y. H., Sugiyama, A., et al. (2009). An $A B C$ transporter mutation alters root exudation of phytochemicals that provoke an overhaul of natural soil microbiota. Plant Physiol. 151, 2006-2017. doi: 10.1104/pp.109.147462

Badri, D. V., Chaparro, J. M., Zhang, R., Shen, Q., and Vivanco, J. M. (2013). Application of natural blends of phytochemicals derived from the root exudates of Arabidopsis to the soil reveal that phenolic-related compounds predominantly modulate the soil microbiome. J. Biol. Chem. 288, 4502-4512. doi: 10.1074/jbc.M112.433300 translational intent, since a number of methodologies and tools need to be combined to design small and effective synthetic communities that can provide the host plants with consistent and predictable outcomes.

\section{AUTHOR CONTRIBUTIONS}

All authors have contributed to the structure and writing of this review, have read and approved it for publication.

\section{FUNDING}

The authors gratefully acknowledge MIUR (Ministry for Education, University and Research) for financial support (MIUR- PRIN 2017, grant number PROSPECT 2017JLN833_005).
Baetz, U., and Martinoia, E. (2014). Root exudates: the hidden part of plant defense. Trends Plant Sci. 19, 90-98. doi: 10.1016/j.tplants.2013.11.006

Bai, Y., Muller, D. B., Srinivas, G., Garrido-Oter, R., Potthoff, E., Rott, M., et al. (2015). Functional overlap of the Arabidopsis leaf and root microbiota. Nature 528, 364-369. doi: 10.1038/nature16192

Bais, H. P., Weir, T. L., Perry, L. G., Gilroy, S., and Vivanco, J. M. (2006). The role of root exudates in rhizosphere interactions with plants and other organisms. Annu. Rev. Plant Biol. 57, 233-266. doi: 10.1146/annurev.arplant.57. 032905.105159

Baker, K. F., and Cook, R. J. (1974). Biological control of plant pathogens (San Francisco, USA: WH Freeman and Company). doi: 10.1017/ S001447970000661X

Bakker, P. A. H. M., Pieterse, C. M. J., De Jonge, R., and Berendsen, R. L. (2018), The soil-borne legacy. Cell 172, 1178-1180. doi: 10.1016/j.cell.2018.02.024

Bardoel, B. W., Van Der Ent, S., Pel, M. J., Tommassen, J., Pieterse, C. M. J., Van Kessel, K. P., et al. (2011). Pseudomonas evades immune recognition of flagellin in both mammals and plants. PloS Pathog. 7, e1002206. doi: 10.1371/ journal.ppat.1002206

Beck, M., Wyrsch, I., Strutt, J., Wimalasekera, R., Webb, A., Boller, T., et al. (2014). Expression patterns of FLAGELLIN SENSING 2 map to bacterial entry sites in plant shoots and roots. J. Exp. Bot. 65, 6487-6498. doi: 10.1093/jxb/eru366

Becker, J., Eisenhauer, N., Scheu, S., and Jousset, A. (2012). Increasing antagonistic interactions cause bacterial communities to collapse at high diversity. Ecol. Lett. 15, 468-474. doi: 10.1111/j.1461-0248.2012.01759.x

Beckers, B., Op De Beeck, M., Weyens, N., Boerjan, W., and Vangronsveld, J. (2017). Structural variability and niche differentiation in the rhizosphere and endosphere bacterial microbiome of field-grown poplar trees. Microbiome 5, 25. doi: 10.1186/s40168-017-0241-2

Bednarek, P., Schneider, B., Svatos, A., Oldham, N. J., and Hahlbrock, K. (2005). Structural complexity, differential response to infection, and tissue specificity of indolic and phenylpropanoid secondary metabolism in Arabidopsis roots. Plant Physiol. 138, 1058-1070. doi: 10.1104/pp.104.057794

Begum, A. A., Leibovitch, S., Migner, P., and Zhang, F. (2001). Specific flavonoids induced nod gene expression and pre-activated nod genes of Rhizobium leguminosarum increased pea (Pisum sativum L.) and lentil (Lens culinaris L.) nodulation in controlled growth chamber environments. J. Exp. Bot. 52, 1537-1543. doi: 10.1093/jexbot/52.360.1537

Beilsmith, K., Thoen, M. P. M., Brachi, B., Gloss, A. D., Khan, M. H., and Bergelson, J. (2019). Genome-wide association studies on the phyllosphere microbiome: embracing complexity in host-microbe interactions. Plant J. 97, 164-181. doi: 10.1111/tpj.14170 
Bell, T. H., Stefani, F. O., Abram, K., Champagne, J., Yergeau, E., Hijri, M., et al. (2016). A diverse soil microbiome degrades more crude oil than specialized bacterial assemblages obtained in culture. Appl. Environ. Microbiol. 82, 55305541. doi: 10.1128/AEM.01327-16

Berendsen, R. L., Pieterse, C. M. J., and Bakker, P. A. H. M. (2012). The rhizosphere microbiome and plant health. Trends Plant Sci. 17, 478-486. doi: 10.1016/j.tplants.2012.04.001

Berendsen, R. L., Van Verk, M. C., Stringlis, I. A., Zamioudis, C., Tommassen, J., Pieterse, C. M. J., et al. (2015). Unearthing the genomes of plant-beneficial Pseudomonas model strains WCS358, WCS374 and WCS417. BMC Genomics 16, 539. doi: $10.1186 / \mathrm{s} 12864-015-1632-\mathrm{z}$

Berendsen, R. L., Vismans, G., Yu, K., Song, Y., De Jonge, R., Burgman, W. P., et al. (2018). Disease-induced assemblage of a plant-beneficial bacterial consortium. ISME J. 12, 1496-1507. doi: 10.1038/s41396-018-0093-1

Bergelson, J., Mittelstrass, J., and Horton, M. W. (2019). Characterizing both bacteria and fungi improves understanding of the Arabidopsis root microbiome. Sci. Rep. 9, 24. doi: 10.1038/s41598-018-37208-z

Berhin, A., De Bellis, D., Franke, R. B., Buono, R. A., Nowack, M. K., and Nawrath, C. (2019). The root cap cuticle: a cell wall structure for seedling establishment and lateral root formation. Cell 176, 1367-1378. doi: 10.1016/ j.cell.2019.01.005

Boller, T., and Felix, G. (2009). A renaissance of elicitors: perception of microbeassociated molecular patterns and danger signals by pattern-recognition receptors. Annu. Rev. Plant Biol. 60, 379-406. doi: 10.1146/annurev.arplant. 57.032905 .105346

Bolton, M. D., Thomma, B. P. H. J., and Nelson, B. D. (2006). Sclerotinia sclerotiorum (Lib.) de Bary: biology and molecular traits of a cosmopolitan pathogen. Mol. Plant Pathol. 7, 1-16. doi: 10.1111/j.1364-3703.2005.00316.x

Bonanomi, G., Antignani, V., Capodilupo, M., and Scala, F. (2010). Identifying the characteristics of organic soil amendments that suppress soilborne plant diseases. Soil Biol. Biochem. 42, 136-144. doi: 10.1016/j.soilbio.2009.10.012

Bonfante, P., and Genre, A. (2010). Mechanisms underlying beneficial plantfungus interactions in mycorrhizal symbiosis. Nat. Commun. 1, 48. doi: 10.1038/ncomms1046

Bressan, M., Roncato, M. A., Bellvert, F., Comte, G., Haichar, F. Z., Achouak, W., et al. (2009). Exogenous glucosinolate produced by Arabidopsis thaliana has an impact on microbes in the rhizosphere and plant roots. ISME J. 3, 1243-1257. doi: 10.1038/ismej.2009.68

Brotman, Y., Landau, U., Cuadros-Inostroza, A., Tohge, T., Fernie, A. R., Chet, I., et al. (2013). Trichoderma-plant root colonization: escaping early plant defense responses and activation of the antioxidant machinery for saline stress tolerance. PloS Pathog. 9, e1003221. doi: 10.1371/journal.ppat.1003221

Brown, D. J., Robertson, W. M., and Trudgill, D. L. (1995). Transmission of viruses by plant nematodes. Annu. Rev. Phytopathol. 33, 223-249. doi: 10.1146/ annurev.py.33.090195.001255

Bruehl, G. W. (1987). Soilborne plant pathogens (New York, USA: Macmillan Publishing Company). doi: 10.1086/415660

Bulgarelli, D., Rott, M., Schlaeppi, K., Ver Loren Van Themaat, E., Ahmadinejad, N., Assenza, F., et al. (2012). Revealing structure and assembly cues for Arabidopsis root-inhabiting bacterial microbiota. Nature 488, 91-95. doi: 10.1038/nature11336

Bulgarelli, D., Schlaeppi, K., Spaepen, S., Ver Loren Van Themaat, E., and SchulzeLefert, P. (2013). Structure and functions of the bacterial microbiota of plants. Annu. Rev. Plant Biol. 64, 807-838. doi: 10.1146/annurev-arplant-050312120106

Bulgarelli, D., Garrido-Oter, R., Munch, P. C., Weiman, A., Droge, J., Pan, Y., et al. (2015). Structure and function of the bacterial root microbiota in wild and domesticated barley. Cell Host Microbe 17, 392-403. doi: 10.1016/ j.chom.2015.01.011

Campbell, R. N. (1996). Fungal transmission of plant viruses. Annu. Rev. Phytopathol. 34, 87-108. doi: 10.1146/annurev.phyto.34.1.87

Cao, Y., Liang, Y., Tanaka, K., Nguyen, C. T., Jedrzejczak, R. P., Joachimiak, A., et al. (2014). The kinase LYK5 is a major chitin receptor in Arabidopsis and forms a chitin-induced complex with related kinase CERK1. eLife 3, e03766. doi: 10.7554/eLife.03766

Carvalhais, L. C., Dennis, P. G., Badri, D. V., Kidd, B. N., Vivanco, J. M., and Schenk, P. M. (2015). Linking jasmonic acid signaling, root exudates, and rhizosphere microbiomes. Mol. Plant-Microbe Interact. 28, 1049-1058. doi: 10.1094/MPMI-01-15-0016-R
Castrillo, G., Teixeira, P. J., Paredes, S. H., Law, T. F., De Lorenzo, L., Feltcher, M. E., et al. (2017). Root microbiota drive direct integration of phosphate stress and immunity. Nature 543, 513-518. doi: 10.1038/nature21417

Cha, J. Y., Han, S., Hong, H. J., Cho, H., Kim, D., Kwon, Y., et al. (2016). Microbial and biochemical basis of a Fusarium wilt-suppressive soil. ISME J. 10, 119-129. doi: 10.1038/ismej.2015.95

Chaparro, J. M., Badri, D. V., Bakker, M. G., Sugiyama, A., Manter, D. K., and Vivanco, J. M. (2013). Root exudation of phytochemicals in Arabidopsis follows specific patterns that are developmentally programmed and correlate with soil microbial functions. PloS One 8, e55731. doi: 10.1371/journal.pone.0055731

Chaparro, J. M., Badri, D. V., and Vivanco, J. M. (2014). Rhizosphere microbiome assemblage is affected by plant development. ISME J. 8, 790-803. doi: 10.1038/ ismej.2013.196

Chapelle, E., Mendes, R., Bakker, P. A. H. M., and Raaijmakers, J. M. (2016). Fungal invasion of the rhizosphere microbiome. ISME J. 10, 265-268. doi: 10.1038/ismej.2015.82

Chellemi, D. O., Gamliel, A., Katan, J., and Subbarao, K. V. (2016). Development and deployment of systems-based approaches for the management of soilborne plant pathogens. Phytopathology 106, 216-225. doi: 10.1094/PHYTO-09-150204-RVW

Chen, Y., Wang, J., Yang, N., Wen, Z., Sun, X., Chai, Y., et al. (2018). Wheat microbiome bacteria can reduce virulence of a plant pathogenic fungus by altering histone acetylation. Nat. Commun. 9, 3429. doi: 10.1038/s41467-018-05683-7

Cheng, Y. T., Zhang, L., and He, S. Y. (2019). Plant-microbe interactions facing environmental challenge. Cell Host Microbe 26, 183-192. doi: 10.1016/ j.chom.2019.07.009

Claesson, M. J., Wang, Q., O'sullivan, O., Greene-Diniz, R., Cole, J. R., Ross, R. P., et al. (2010). Comparison of two next-generation sequencing technologies for resolving highly complex microbiota composition using tandem variable $16 \mathrm{~S}$ rRNA gene regions. Nucleic Acids Res. 38, e200. doi: 10.1093/nar/gkq873

Coleman, J. J. (2016). The Fusarium solani species complex: ubiquitous pathogens of agricultural importance. Mol. Plant Pathol. 17, 146-158. doi: 10.1111/ mpp. 12289

Compant, S., Samad, A., Faist, H., and Sessitsch, A. (2019). A review on the plant microbiome: Ecology, functions, and emerging trends in microbial application. J. Adv. Res. 19, 29-37. doi: 10.1016/j.jare.2019.03.004

Cook, R. J., and Rovira, A. D. (1976). Role of bacteria in biological control of Gaeumannomyces graminis by suppressive soils. Soil Biol. Biochem. 8, 269-273. doi: 10.1094/PHYTO-03-17-0111-RVW

Cook, R. J. (2014). Plant health management: Pathogen suppressive soils. (Amsterdam, Netherlands: Elsevier). doi: 10.1016/0038-0717(76)90056-0

Cotton, T. E. A., Petriacq, P., Cameron, D. D., Meselmani, M. A., Schwarzenbacher, R., Rolfe, S. A., et al. (2019). Metabolic regulation of the maize rhizobiome by benzoxazinoids. ISME J. 13, 1647-1658. doi: 10.1038/ s41396-019-0375-2

Couto, D., and Zipfel, C. (2016). Regulation of pattern recognition receptor signalling in plants. Nat. Rev. Immunol. 16, 537-552. doi: 10.1038/nri.2016.77

Cretoiu, M. S., Korthals, G. W., Visser, J. H., and Van Elsas, J. D. (2013). Chitin amendment increases soil suppressiveness toward plant pathogens and modulates the actinobacterial and oxalobacteraceal communities in an experimental agricultural field. Appl. Environ. Microbiol. 79, 5291-5301. doi: 10.1128/AEM.01361-13

Dakora, F. D., and Phillips, D. A. (2002). Root exudates as mediators of mineral acquisition in low-nutrient environments. Plant Soil 245, 35-47. doi: 10.1023/ A:1020809400075

De Coninck, B., Timmermans, P., Vos, C., Cammue, B. P., and Kazan, K. (2015). What lies beneath: belowground defense strategies in plants. Trends In Plant Sci. 20, 91-101. doi: 10.1016/j.tplants.2014.09.007

De Jaeger, N., De La Providencia, I. E., De Boulois, H. D., and Declerck, S. (2011). Trichoderma harzianum might impact phosphorus transport by arbuscular mycorrhizal fungi. FEMS Microbiol. Ecol. 77, 558-567. doi: 10.1111/j.15746941.2011.01135.x

De Souza, R. S., Okura, V. K., Armanhi, J. S., Jorrin, B., Lozano, N., Da Silva, M. J., et al. (2016). Unlocking the bacterial and fungal communities assemblages of sugarcane microbiome. Sci. Rep. 6, 28774. doi: 10.1038/srep28774

Dodds, P. N., and Rathjen, J. P. (2010). Plant immunity: towards an integrated view of plant-pathogen interactions. Nat. Rev. Genet. 11, 539-548. doi: $10.1038 / \operatorname{nrg} 2812$ 
Dombrowski, N., Schlaeppi, K., Agler, M. T., Hacquard, S., Kemen, E., GarridoOter, R., et al. (2017). Root microbiota dynamics of perennial Arabis alpina are dependent on soil residence time but independent of flowering time. ISME J. 11, 43-55. doi: 10.1038/ismej.2016.109

Driouich, A., Follet-Gueye, M. L., Vicre-Gibouin, M., and Hawes, M. (2013). Root border cells and secretions as critical elements in plant host defense. Curr. Opin. Plant Biol. 16, 489-495. doi: 10.1016/j.pbi.2013.06.010

Duca, D., Lorv, J., Patten, C. L., Rose, D., and Glick, B. R. (2014). Indole-3-acetic acid in plant-microbe interactions. Antonie Van Leeuwenhoek 106, 85-125. doi: 10.1007/s10482-013-0095-y

Duran, P., Thiergart, T., Garrido-Oter, R., Agler, M., Kemen, E., Schulze-Lefert, P., et al. (2018). Microbial interkingdom interactions in roots promote Arabidopsis survival. Cell 175, 973-983. doi: 10.1016/j.cell.2018.10.020

Edwards, J., Johnson, C., Santos-Medellin, C., Lurie, E., Podishetty, N. K., Bhatnagar, S., et al. (2015). Structure, variation, and assembly of the rootassociated microbiomes of rice. Proc. Natl. Acad. Sci. U.S.A. 112, 911-920. doi: $10.1073 /$ pnas. 1414592112

Eng, A., and Borenstein, E. (2019). Microbial community design: methods, applications, and opportunities. Curr. Opin. Biotechnol. 58, 117-128. doi: 10.1016/j.copbio.2019.03.002

Fabianska, I., Gerlach, N., Almario, J., and Bucher, M. (2019). Plant-mediated effects of soil phosphorus on the root-associated fungal microbiota in Arabidopsis thaliana. New Phytol. 221, 2123-2137. doi: 10.1111/nph.15538

Fan, M., Xiao, X., Guo, Y., Zhang, J., Wang, E., Chen, W., et al. (2018). Enhanced phytoremdiation of Robinia pseudoacacia in heavy metalcontaminated soils with rhizobia and the associated bacterial community structure and function. Chemosphere 197, 729-740. doi: 10.1016/ j.chemosphere.2018.01.102

Field, K. J., Pressel, S., Duckett, J. G., Rimington, W. R., and Bidartondo, M. I. (2015). Symbiotic options for the conquest of land. Trends Ecol. Evol. 30, 477486. doi: 10.1016/j.tree.2015.05.007

Finkel, O. M., Castrillo, G., Paredes, S. H., Salas Gonzalez, I., and Dangl, J. L. (2017). Understanding and exploiting plant beneficial microbes. Curr. Opin. Plant Biol. 38, 155-163. doi: 10.1016/j.pbi.2017.04.018

Finkel, O. M., Salas-González, I., Castrillo, G., Law, T. F., Conway, J. M., Teixeira, P. J. P. L., et al. (2019). Root development is maintained by specific bacteriabacteria interactions within a complex microbiome. bioRxiv 645655. doi: $10.1101 / 645655$

Fourcroy, P., Siso-Terraza, P., Sudre, D., Saviron, M., Reyt, G., Gaymard, F.,, et al. (2014). Involvement of the ABCG37 transporter in secretion of scopoletin and derivatives by Arabidopsis roots in response to iron deficiency. New Phytol. 201, 155-167. doi: 10.1111/nph.12471

Fourcroy, P., Tissot, N., Gaymard, F., Briat, J. F., and Dubos, C. (2016). Facilitated Fe nutrition by phenolic compounds excreted by the Arabidopsis ABCG37/ PDR9 transporter requires the IRT1/FRO2 high-affinity root $\mathrm{Fe}(2+)$ transport system. Mol. Plant 9, 485-488. doi: 10.1016/j.molp.2015.09.010

Galan, J. E., and Collmer, A. (1999). Type III secretion machines: bacterial devices for protein delivery into host cells. Science 284, 1322-1328. doi: 10.1126/ science.284.5418.1322

Garnica-Vergara, A., Barrera-Ortiz, S., Munoz-Parra, E., Raya-Gonzalez, J., Mendez-Bravo, A., Macias-Rodriguez, L., et al. (2016). The volatile 6-pentyl$2 \mathrm{H}$-pyran-2-one from Trichoderma atroviride regulates Arabidopsis thaliana root morphogenesis via auxin signaling and Ethylene Insensitive 2 functioning. New Phytol. 209, 1496-1512. doi: 10.1111/nph.13725

Gaspar, Y. M., Nam, J., Schultz, C. J., Lee, L. Y., Gilson, P. R., Gelvin, S. B., et al. (2004). Characterization of the Arabidopsis lysine-rich arabinogalactanprotein AtAGP17 mutant (rat1) that results in a decreased efficiency of Agrobacterium transformation. Plant Physiol. 135, 2162-2171. doi: 10.1104/ pp.104.045542

Geldner, N. (2013). The endodermis. Annu. Rev. Plant Biol. 64, 531-558. doi: 10.1146/annurev-arplant-050312-120050

Gilbert, J. A., Quinn, R. A., Debelius, J., Xu, Z. Z., Morton, J., Garg, N., et al. (2016). Microbiome-wide association studies link dynamic microbial consortia to disease. Nature 535, 94-103. doi: 10.1038/nature18850

Gkarmiri, K., Mahmood, S., Ekblad, A., Alstrom, S., Hogberg, N., and Finlay, R. (2017). Identifying the active microbiome associated with roots and rhizosphere soil of oilseed rape. Appl. Environ. Microbiol. 83, e01938e01917. doi: 10.1128/AEM.01938-17
Glick, B. R. (2014). Bacteria with ACC deaminase can promote plant growth and help to feed the world. Microbiol. Res. 169, 30-39. doi: 10.1016/ j.micres.2013.09.009

Gomez Exposito, R., De Bruijn, I., Postma, J., and Raaijmakers, J. M. (2017). Current insights into the role of rhizosphere bacteria in disease suppressive soils. Front. Microbiol. 8, 2529. doi: 10.3389/fmicb.2017.02529

Gomez-Gomez, L., and Boller, T. (2000). FLS2: an LRR receptor-like kinase involved in the perception of the bacterial elicitor flagellin in Arabidopsis. Mol. Cell 5, 1003-1011. doi: 10.1016/s1097-2765(00)80265-8

Gomez-Gomez, L., Felix, G., and Boller, T. (1999). A single locus determines sensitivity to bacterial flagellin in Arabidopsis thaliana. Plant J. 18, 277-284. doi: 10.1046/j.1365-313x.1999.00451.x

Gonzalez, M., Pujol, M., Metraux, J. P., Gonzalez-Garcia, V., Bolton, M. D., and Borras-Hidalgo, O. (2011). Tobacco leaf spot and root rot caused by Rhizoctonia solani Kuhn. Mol. Plant Pathol. 12, 209-216. doi: 10.1111/ j.1364-3703.2010.00664.x

Gonzalez, E., Pitre, F. E., Page, A. P., Marleau, J., Guidi Nissim, W., St-Arnaud, M., et al. (2018). Trees, fungi and bacteria: tripartite metatranscriptomics of a root microbiome responding to soil contamination. Microbiome 6, 53. doi: 10.1186/ s40168-018-0432-5

Hacquard, S., Spaepen, S., Garrido-Oter, R., and Schulze-Lefert, P. (2017). Interplay between innate immunity and the plant microbiota. Annu. Rev. Phytopathol. 55, 565-589. doi: 10.1146/annurev-phyto-080516-035623

Hao, W. Y., Ren, L. X., Ran, W., and Shen, Q. R. (2010). Allelopathic effects of root exudates from watermelon and rice plants on Fusarium oxysporum f.sp. niveum. Plant Soil 336, 485-497. doi: 10.1007/s11104-010-0505-0

Harman, G. E., Howell, C. R., Viterbo, A., Chet, I., and Lorito, M. (2004). Trichoderma species-opportunistic, avirulent plant symbionts. Nat. Rev. Microbiol. 2, 43-56. doi: 10.1038/nrmicro797

Hassani, M. A., Duran, P., and Hacquard, S. (2018). Microbial interactions within the plant holobiont. Microbiome 6, 58. doi: 10.1186/s40168-018-0445-0

Helfrich, E. J. N., Vogel, C. M., Ueoka, R., Schafer, M., Ryffel, F., Muller, D. B., et al. (2018). Bipartite interactions, antibiotic production and biosynthetic potential of the Arabidopsis leaf microbiome. Nat. Microbiol. 3, 909-919. doi: 10.1038/ s41564-018-0200-0

Hiltner, L. (1904). Uber neure Erfahrungen und probleme aufdem gebeit der bodenbackteriologie und unter besonderer berucksichtigung der grundungung und brache. Arb. Dtsch. Landwirtsch. Gesellschaft 98, 59-78.

Hiruma, K., Gerlach, N., Sacristan, S., Nakano, R. T., Hacquard, S., Kracher, B., et al. (2016). Root endophyte Colletotrichum tofieldiae confers plant fitness benefits that are phosphate status dependent. Cell 165, 464-474. doi: 10.1016/ j.cell.2016.02.028

Hu, J., Wei, Z., Friman, V. P., Gu, S. H., Wang, X. F., Eisenhauer, N., et al. (2016). Probiotic diversity enhances rhizosphere microbiome function and plant disease suppression. MBio 7, e01790-e01716. doi: 10.1128/mBio. 01790-16

Hu, J., Wei, Z., Weidner, S., Friman, V. P., Xu, Y. C., Shen, Q. R., et al. (2017). Probiotic Pseudomonas communities enhance plant growth and nutrient assimilation via diversity-mediated ecosystem functioning. Soil Biol. Biochem. 113, 122-129. doi: 10.1016/j.soilbio.2017.05.029

Hu, L., Robert, C. A. M., Cadot, S., Zhang, X., Ye, M., Li, B., et al. (2018). Root exudate metabolites drive plant-soil feedbacks on growth and defense by shaping the rhizosphere microbiota. Nat. Commun. 9, 2738. doi: 10.1038/ s41467-018-05122-7

Huang, A. C., Jiang, T., Liu, Y. X., Bai, Y. C., Reed, J., Qu, B., et al. (2019). A specialized metabolic network selectively modulates Arabidopsis root microbiota. Science 364, eaau6389. doi: 10.1126/science.aau6389

Jacobs, S., Zechmann, B., Molitor, A., Trujillo, M., Petutschnig, E., Lipka, V., et al. (2011). Broad-spectrum suppression of innate immunity is required for colonization of Arabidopsis roots by the fungus Piriformospora indica. Plant Physiol. 156, 726-740. doi: 10.1104/pp.111.176446

Jacoby, R. P., and Kopriva, S. (2018). Metabolic niches in the rhizosphere microbiome: new tools and approaches to analyse metabolic mechanisms of plant-microbe nutrient exchange. J. Exp. Bot. 70, 1087-1094. doi: 10.1093/jxb/ ery 438

Jacoby, R., Peukert, M., Succurro, A., Koprivova, A., and Kopriva, S. (2017). The role of soil microorganisms in plant mineral nutrition-current knowledge and future directions. Front. Plant Sci. 8, 1617. doi: 10.3389/fpls.2017.01617 
Jansson, J. K., and Baker, E. S. (2016). A multi-omic future for microbiome studies. Nat. Microbiol. 1, 16049. doi: 10.1038/nmicrobiol.2016.49

Jiang, Y., Wang, W., Xie, Q., Liu, N., Liu, L., Wang, D., et al. (2017). Plants transfer lipids to sustain colonization by mutualistic mycorrhizal and parasitic fungi. Science 356, 1172-1175. doi: 10.1126/science.aam9970

Jimenez-Guerrero, I., Perez-Montano, F., Monreal, J. A., Preston, G. M., Fones, H., Vioque, B., et al. (2015). The Sinorhizobium (Ensifer) fredii HH103 type 3 secretion system suppresses early defense responses to effectively nodulate soybean. Mol. Plant-Microbe Interact. 28, 790-799. doi: 10.1094/MPMI-01-150020-R

Jin, C. W., You, G. Y., He, Y. F., Tang, C., Wu, P., and Zheng, S. J. (2007). Iron deficiency-induced secretion of phenolics facilitates the reutilization of root apoplastic iron in red clover. Plant Physiol. 144, 278-285. doi: 10.1104/ pp.107.095794

Jung, S. C., Martinez-Medina, A., Lopez-Raez, J. A., and Pozo, M. J. (2012). Mycorrhiza-induced resistance and priming of plant defenses. J. Chem. Ecol. 38, 651-664. doi: 10.1007/s10886-012-0134-6

Kai, K., Mizutani, M., Kawamura, N., Yamamoto, R., Tamai, M., Yamaguchi, H., et al. (2008). Scopoletin is biosynthesized via ortho-hydroxylation of feruloyl CoA by a 2-oxoglutarate-dependent dioxygenase in Arabidopsis thaliana. Plant J. 55, 989-999. doi: 10.1111/j.1365-313X.2008.03568.x

Katan, J. (2017). Diseases caused by soilborne pathogens: biology, management and challenges. J. Plant Pathol. 99, 305-315. doi: 10.4454/jpp.v99i2.3862

Kloepper, J. W., Ryu, C. M., and Zhang, S. (2004). Induced systemic resistance and promotion of plant growth by Bacillus spp. Phytopathology 94, 1259-1266. doi: 10.1094/PHYTO.2004.94.11.1259

Kloppholz, S., Kuhn, H., and Requena, N. (2011). A secreted fungal effector of Glomus intraradices promotes symbiotic biotrophy. Curr. Biol. 21, 1204-1209. doi: 10.1016/j.cub.2011.06.044

Klosterman, S. J., Atallah, Z. K., Vallad, G. E., and Subbarao, K. V. (2009). Diversity, pathogenicity, and management of Verticillium species. Annu. Rev. Phytopathol. 47, 39-62. doi: 10.1146/annurev-phyto-080508-081748

Koike, S., Subbarao, K., Davis, R. M., and Turini, T. (2003). Vegetable diseases caused by soilborne pathogens. UCANR Publications. 8099:12.

Koprivova, A., Schuck, S., Jacoby, R. P., Klinkhammer, I., Welter, B., Leson, L., et al. (2019). Root-specific camalexin biosynthesis controls the plant growthpromoting effects of multiple bacterial strains. Proc. Natl. Acad. Sci. U. S. A. 116, 15735-15744. doi: 10.1073/pnas.1818604116

Kuiper, I., Lagendijk, E. L., Bloemberg, G. V., and Lugtenberg, B. J. (2004). Rhizoremediation: a beneficial plant-microbe interaction. Mol. Plant-Microbe Interact. 17, 6-15. doi: 10.1094/MPMI.2004.17.1.6

Kunze, G., Zipfel, C., Robatzek, S., Niehaus, K., Boller, T., and Felix, G. (2004). The $\mathrm{N}$ terminus of bacterial elongation factor Tu elicits innate immunity in Arabidopsis plants. Plant Cell 16, 3496-3507. doi: 10.1105/tpc.104.026765

Kwak, M. J., Kong, H. G., Choi, K., Kwon, S. K., Song, J. Y., Lee, J., et al. (2018). Rhizosphere microbiome structure alters to enable wilt resistance in tomato. Nat. Biotechnol. 36, 1100-1109. doi: 10.1038/nbt.4232

Lamour, K. H., Stam, R., Jupe, J., and Huitema, E. (2012). The oomycete broadhost-range pathogen Phytophthora capsici. Mol. Plant Pathol. 13, 329-337. doi: 10.1111/j.1364-3703.2011.00754.x

Lawson, C. E., Harcombe, W. R., Hatzenpichler, R., Lindemann, S. R., Loffler, F. E., O'malley, M. A., et al. (2019). Common principles and best practices for engineering microbiomes. Nat. Rev. Microbiol. 17, 725-741. doi: 10.1038/ s41579-019-0255-9

Lebeis, S. L., Paredes, S. H., Lundberg, D. S., Breakfield, N., Gehring, J., Mcdonald, M., et al. (2015). Salicylic acid modulates colonization of the root microbiome by specific bacterial taxa. Science 349, 860-864. doi: 10.1126/science.aaa8764

Lee, B., Lee, S., and Ryu, C. M. (2012). Foliar aphid feeding recruits rhizosphere bacteria and primes plant immunity against pathogenic and non-pathogenic bacteria in pepper. Ann. Bot. 110, 281-290. doi: 10.1093/aob/mcs055

Lee, H. R., Lee, S., Park, S., Van Kleeff, P. J. M., Schuurink, R. C., and Ryu, C. M. (2018). Transient expression of whitefly effectors in Nicotiana benthamiana leaves activates systemic immunity against the leaf pathogen Pseudomonas syringae and soil-borne pathogen Ralstonia solanacearum. Front. Ecol. Evol. 6, 90. doi: $10.3389 /$ fevo. 2018.00090

Leff, J. W., Lynch, R. C., Kane, N. C., and Fierer, N. (2017). Plant domestication and the assembly of bacterial and fungal communities associated with strains of the common sunflower, Helianthus annuus. New Phytol. 214, 412-423. doi: $10.1111 /$ nph. 14323

Levy, A., Conway, J. M., Dangl, J. L., and Woyke, T. (2018). Elucidating bacterial gene functions in the plant microbiome. Cell Host Microbe 24, 475-485. doi: 10.1016/j.chom.2018.09.005

Liu, H., Macdonald, C. A., Cook, J., Anderson, I. C., and Singh, B. K. (2019a). An ecological loop: Host microbiomes across multitrophic interactions. Trends Ecol. Evol. 34, 1118-1130. doi: 10.1016/j.tree.2019.07.011

Liu, Y., Zhu, A., Tan, H., Cao, L., and Zhang, R. (2019b). Engineering banana endosphere microbiome to improve Fusarium wilt resistance in banana. Microbiome 7, 74. doi: 10.1186/s40168-019-0690-x

Lombardi, N., Vitale, S., Turra, D., Reverberi, M., Fanelli, C., Vinale, F., et al. (2018). Root exudates of stressed plants stimulate and attract Trichoderma soil fungi. Mol. Plant-Microbe Interact. 31, 982-994. doi: 10.1094/MPMI-12-170310-R

Loper, J. E., Hassan, K. A., Mavrodi, D. V., Davis Ii, E. W., Lim, C. K., Shaffer, B. T., et al. (2012). Comparative genomics of plant-associated Pseudomonas spp.: insights into diversity and inheritance of traits involved in multitrophic interactions. PloS Genet. 8, e1002784. doi: 10.1371/journal.pgen.1002784

Loreau, M., Naeem, S., Inchausti, P., Bengtsson, J., Grime, J. P., Hector, A., et al. (2001). Biodiversity and ecosystem functioning: current knowledge and future challenges. Science 294, 804-808. doi: 10.1126/science.1064088

Lugtenberg, B., and Kamilova, F. (2009). Plant-growth-promoting rhizobacteria. Annu. Rev. Microbiol. 63, 541-556. doi: 10.1146/annurev.micro.62. 081307.162918

Lundberg, D. S., Lebeis, S. L., Paredes, S. H., Yourstone, S., Gehring, J., Malfatti, S., et al. (2012). Defining the core Arabidopsis thaliana root microbiome. Nature 488, 86-90. doi: 10.1038/nature11237

Maclean, A. M., Bravo, A., and Harrison, M. J. (2017). Plant signaling and metabolic pathways enabling arbuscular mycorrhizal symbiosis. Plant Cell 29, 2319-2335. doi: 10.1105/tpc.17.00555

Manganiello, G., Sacco, A., Ercolano, M. R., Vinale, F., Lanzuise, S., Pascale, A., et al. (2018). Modulation of tomato response to Rhizoctonia solani by Trichoderma harzianum and its secondary metabolite harzianic Acid. Front. In Microbiol. 9, 1966. doi: 10.3389/fmicb.2018.01966

Marhavy, P., Kurenda, A., Siddique, S., Denervaud Tendon, V., Zhou, F., Holbein, J., et al. (2019). Single-cell damage elicits regional, nematode-restricting ethylene responses in roots. EMBO J. 38, e100972. doi: 10.15252/embj.2018100972

Martin, F. M., Uroz, S., and Barker, D. G. (2017). Ancestral alliances: Plant mutualistic symbioses with fungi and bacteria. Science 356, eaad4501. doi: 10.1126/science.aad4501

Martinez-Medina, A., Flors, V., Heil, M., Mauch-Mani, B., Pieterse, C. M. J., Pozo, M. J., et al. (2016). Recognizing plant defense priming. Trends Plant Sci. 21, 818-822. doi: 10.1016/j.tplants.2016.07.009

Martinez-Medina, A., Van Wees, S. C. M., and Pieterse, C. M. J. (2017). Airborne signals by Trichoderma fungi stimulate iron uptake responses in roots resulting in priming of jasmonic acid-dependent defences in shoots of Arabidopsis thaliana and Solanum lycopersicum. Plant Cell Environ. 40, 2691-2705. doi: 10.1111/pce. 13016

Massalha, H., Korenblum, E., Malitsky, S., Shapiro, O. H., and Aharoni, A. (2017). Live imaging of root-bacteria interactions in a microfluidics setup. Proc. Natl. Acad. Sci. U. S. A. 114, 4549-4554. doi: 10.1073/pnas.1618584114

Matthews, A., Pierce, S., Hipperson, H., and Raymond, B. (2019). Rhizobacterial community assembly patterns vary between crop species. Front. Microbiol. 10, 581. doi: $10.3389 /$ fmicb.2019.00581

Mavrodi, D. V., Joe, A., Mavrodi, O. V., Hassan, K. A., Weller, D. M., Paulsen, I. T., et al. (2011). Structural and functional analysis of the type III secretion system from Pseudomonas fluorescens Q8r1-96. J. Bacteriol. 193, 177-189. doi: 10.1128/JB.00895-10

Mazzola, M. (2002). Mechanisms of natural soil suppressiveness to soilborne diseases. Antonie Van Leeuwenhoek 81, 557-564. doi: 10.1023/ A:1020557523557

Mendes, R., Kruijt, M., De Bruijn, I., Dekkers, E., Van Der Voort, M., Schneider,? J.?H., et al. (2011). Deciphering the rhizosphere microbiome for diseasesuppressive bacteria. Science 332, 1097-1100. doi: 10.1126/science.1203980

Mendes, L. W., Raaijmakers, J. M., De Hollander, M., Mendes, R., and Tsai, S. M. (2018). Influence of resistance breeding in common bean on rhizosphere 
microbiome composition and function. ISME J. 12, 212-224. doi: 10.1038/ ismej.2017.158

Michielse, C. B., and Rep, M. (2009). Pathogen profile update: Fusarium oxysporum. Mol. Plant Pathol. 10, 311-324. doi: 10.1111/j.13643703.2009.00538.x

Millet, Y. A., Danna, C. H., Clay, N. K., Songnuan, W., Simon, M. D., WerckReichhart, D., et al. (2010). Innate immune responses activated in Arabidopsis roots by microbe-associated molecular patterns Plant Cell 22, 973-990. doi: 10.1105/tpc.109.069658

Miya, A., Albert, P., Shinya, T., Desaki, Y., Ichimura, K., Shirasu, K., et al. (2007). CERK1, a LysM receptor kinase, is essential for chitin elicitor signaling in Arabidopsis. Proc. Natl. Acad. Sci. U.S.A. 104, 19613-19618. doi: 10.1073/pnas.0705147104

Molina-Romero, D., Baez, A., Quintero-Hernandez, V., Castaneda-Lucio, M., Fuentes-Ramirez, L. E., Bustillos-Cristales, M. D. R., et al. (2017). Compatible bacterial mixture, tolerant to desiccation, improves maize plant growth. PloS One 12, e0187913. doi: 10.1371/journal.pone.0187913

Muller, D. B., Vogel, C., Bai, Y., and Vorholt, J. A. (2016). The plant microbiota: systems-level insights and perspectives. Annu. Rev. Genet. 50, 211-234. doi: 10.1146/annurev-genet-120215-034952

Naseer, S., Lee, Y., Lapierre, C., Franke, R., Nawrath, C., and Geldner, N. (2012). Casparian strip diffusion barrier in Arabidopsis is made of a lignin polymer without suberin. Proc. Natl. Acad. Sci. U.S.A. 109, 10101-10106. doi: 10.1073/ pnas. 1205726109

Neal, A. L., Ahmad, S., Gordon-Weeks, R., and Ton, J. (2012). Benzoxazinoids in root exudates of maize attract Pseudomonas putida to the rhizosphere. PloS One 7, e35498. doi: 10.1371/journal.pone.0035498

Niu, B., Paulson, J. N., Zheng, X., and Kolter, R. (2017). Simplified and representative bacterial community of maize roots. Proc. Natl. Acad. Sci. U. S. A. 114, 24502459. doi: $10.1073 /$ pnas. 1616148114

O' Banion, B., O' Neal, L., Alexandre, G., and Lebeis, S. (2019). Bridging the gap between single-strain and community-level plant-microbe chemical interactions. Mol. Plant-Microbe Interact. doi: 10.1094/MPMI-1004-1019-0115-CR

Ofek-Lalzar, M., Sela, N., Goldman-Voronov, M., Green, S. J., Hadar, Y., and Minz, D. (2014). Niche and host-associated functional signatures of the root surface microbiome. Nat. Commun. 5, 4950. doi: 10.1038/ncomms5950

Okubara, P. A., and Paulitz, T. C. (2005). Root defense responses to fungal pathogens: a molecular perspective. Plant and Soil, 274, 215-226. doi: 10.1007/ s11104-004-7328-9

Oldroyd, G. E. (2013). Speak, friend, and enter: signalling systems that promote beneficial symbiotic associations in plants. Nat. Rev. Microbiol. 11, 252-263. doi: $10.1038 /$ nrmicro2990

Ongena, M., and Jacques, P. (2008). Bacillus lipopeptides: versatile weapons for plant disease biocontrol. Trends Microbiol. 16, 115-125.

Papadopoulou, K., Melton, R. E., Leggett, M., Daniels, M. J., and Osbourn, A. E. (1999). Compromised disease resistance in saponin-deficient plants. Proc. Natl. Acad. Sci. U. S. A. 96, 12923-12928. doi: 10.1073/pnas.96.22.12923

Paredes, S. H., Gao, T. X., Law, T. F., Finkel, O. M., Mucyn, T., Teixeira, P. J. P. L., et al. (2018). Design of synthetic bacterial communities for predictable plant phenotypes. PloS Biol. 16, e2003962. doi: 10.1371/journal. pbio. 2003962

Parniske, M. (2008). Arbuscular mycorrhiza: the mother of plant root endosymbioses. Nat. Rev. Microbiol. 6, 763-775. doi: 10.1038/nrmicro1987

Parratt, S. R., and Laine, A. L. (2018). Pathogen dynamics under both bottom-up host resistance and top-down hyperparasite attack. J. Appl. Ecol. 55, 29762985. doi: $10.1111 / 1365-2664.13185$

Patkar, R. N., and Naqvi, N. I. (2017). Fungal manipulation of hormone-regulated plant defense. PloS Pathog. 13, e1006334. doi: 10.1371/journal.ppat.1006334

Peeters, N., Guidot, A., Vailleau, F., and Valls, M. (2013). Ralstonia solanacearum, a widespread bacterial plant pathogen in the post-genomic era. Mol. Plant Pathol. 14, 651-662. doi: 10.1111/mpp.12038

Pel, M. J., Van Dijken, A. J., Bardoel, B. W., Seidl, M. F., Van Der Ent, S., Van Strijp, J. A., et al. (2014). Pseudomonas syringae evades host immunity by degrading flagellin monomers with alkaline protease AprA. Mol. PlantMicrobe Interact. 27, 603-610. doi: 10.1094/MPMI-02-14-0032-R

Penton, C. R., Gupta, V. V., Tiedje, J. M., Neate, S. M., Ophel-Keller, K., Gillings, M., et al. (2014). Fungal community structure in disease suppressive soils assessed by 28S LSU gene sequencing. PloS One 9, e93893. doi: 10.1371/journal. pone.0093893
Perez-Garcia, O., Lear, G., and Singhal, N. (2016). Metabolic network modeling of microbial interactions in natural and engineered environmental systems. Front. Microbiol. 7, 673. doi: 10.3389/fmicb.2016.00673

Pérez-Jaramillo, J. E., Mendes, R., and Raaijmakers, J. M. (2016). Impact of plant domestication on rhizosphere microbiome assembly and functions. Plant Mol. Biol. 90, 635-644. doi: 10.1007/s11103-015-0337-7

Pérez-Jaramillo, J. E., Carrion, V. J., Bosse, M., Ferrao, L. F. V., De Hollander, M., Garcia, A.a.F., et al. (2017). Linking rhizosphere microbiome composition of wild and domesticated Phaseolus vulgaris to genotypic and root phenotypic traits. ISME J. 11, 2244-2257. doi: 10.1038/ismej.2017.85

Perez-Jaramillo, J. E., Carrion, V. J., De Hollander, M., and Raaijmakers, J. M. (2018). The wild side of plant microbiomes. Microbiome 6, 143. doi: 10.1186/ s40168-018-0519-z

Pérez-Jaramillo, J. E., De Hollander, M., Ramírez, C. A., Mendes, R., Raaijmakers, J. M., and Carrión, V. J. (2019). Deciphering rhizosphere microbiome assembly of wild and modern common bean (Phaseolus vulgaris) in native and agricultural soils from Colombia. Microbiome 7, 114.

Pieterse, C. M. J., Leon-Reyes, A., Van Der Ent, S., and Van Wees, S. C. M. (2009). Networking by small-molecule hormones in plant immunity. Nat. Chem. Biol. 5, 308-316. doi: 10.1038/nchembio.164

Pieterse, C. M. J., Van Der Does, D., Zamioudis, C., Leon-Reyes, A., and Van Wees, S. C. M. (2012). Hormonal modulation of plant immunity. Annu. Rev. Cell Dev. Biol. 28, 489-521. doi: 10.1146/annurev-cellbio-092910-154055

Pieterse, C. M. J., Zamioudis, C., Berendsen, R. L., Weller, D. M., Van Wees, S. C. M., and Bakker, P. A. H. M. (2014). Induced systemic resistance by beneficial microbes. Annu. Rev. Phytopathol. 52, 347-375. doi: 10.1146/annurev-phyto082712-102340

Pieterse, C. M. J., De Jonge, R., and Berendsen, R. L. (2016). The soil-borne supremacy. Trends Plant Sci. 21, 171-173. doi: 10.1016/j.tplants.2016.01.018

Pimentel, D. L., McLaughlin, A., Zepp, B., Lakitan, T., Kraus, P., Kleinman, F., et al. (1991). Environmental and economic effects of reducing pesticide use. Bioscience, 41, 492-409. doi: 10.2307/1311747

Pini, F., East, A. K., Appia-Ayme, C., Tomek, J., Karunakaran, R., MendozaSuarez, M., et al. (2017). Bacterial biosensors for in vivo spatiotemporal mapping of root secretion. Plant Physiol. 174, 1289-1306. doi: 10.1104/ pp.16.01302

Plett, J. M., Kemppainen, M., Kale, S. D., Kohler, A., Legue, V., Brun, A., et al. (2011). A secreted effector protein of Laccaria bicolor is required for symbiosis development. Curr. Biol. 21, 1197-1203. doi: 10.1016/j.cub.2011.05.033

Plett, J. M., Daguerre, Y., Wittulsky, S., Vayssieres, A., Deveau, A., Melton, S. J., et al. (2014a). Effector MiSSP7 of the mutualistic fungus Laccaria bicolor stabilizes the Populus JAZ6 protein and represses jasmonic acid (JA) responsive genes. Proc. Natl. Acad. Sci. U. S. A. 111, 8299-8304. doi: 10.1073/pnas.1322671111

Plett, J. M., Khachane, A., Ouassou, M., Sundberg, B., Kohler, A., and Martin, F. (2014b). Ethylene and jasmonic acid act as negative modulators during mutualistic symbiosis between Laccaria bicolor and Populus roots. New Phytol. 202, 270-286. doi: 10.1111/nph.12655

Poncini, L., Wyrsch, I., Denervaud Tendon, V., Vorley, T., Boller, T., Geldner, N., et al. (2017). In roots of Arabidopsis thaliana, the damage-associated molecular pattern AtPep1 is a stronger elicitor of immune signalling than flg22 or the chitin heptamer. PloS One 12, e0185808. doi: 10.1371/ journal.pone. 0185808

Poole, P., Ramachandran, V., and Terpolilli, J. (2018). Rhizobia: from saprophytes to endosymbionts. Nat. Rev. Microbiol. 16, 291-303. doi: 10.1038/ nrmicro.2017.171

Poudel, R., Jumpponen, A., Schlatter, D. C., Paulitz, T. C., Gardener, B. B., Kinkel, L. L., et al. (2016). Microbiome networks: a systems framework for identifying candidate microbial assemblages for disease management. Phytopathology 106, 1083-1096. doi: 10.1094/PHYTO-02-16-0058-FI

Preston, G. M., Bertrand, N., and Rainey, P. B. (2001). Type III secretion in plant growth-promoting Pseudomonas fluorescens SBW25. Mol. Microbiol. 41, 9991014. doi: $10.1046 /$ j.1365-2958.2001.02560.x

Raaijmakers, J. M., and Mazzola, M. (2016). Soil immune responses. Science 352, 1392-1393. doi: 10.1126/science.aaf3252

Raaijmakers, J. M., and Weller, D. M. (1998). Natural plant protection by 2,4diacetylphloroglucinol - producing Pseudomonas spp. in take-all decline soils. Mol. Plant-Microbe Interact. 11. doi: 10.1094/MPMI.1998.11.2.144 
Raaijmakers, J. M., Paulitz, T. C., Steinberg, C., Alabouvette, C., and MoenneLoccoz, Y. (2009). The rhizosphere: a playground and battlefield for soilborne pathogens and beneficial microorganisms. Plant Soil 321, 341-361. doi: 10.1007/s11104-008-9568-6

Raaijmakers, J. M., De Bruijn, I., Nybroe, O., and Ongena, M. (2010). Natural functions of lipopeptides from Bacillus and Pseudomonas: more than surfactants and antibiotics. FEMS Microbiol. Rev. 34, 1037-1062. doi: 10.1111/j.1574-6976.2010.00221.x

Rajniak, J., Giehl, R. F. H., Chang, E., Murgia, I., Von Wiren, N., and Sattely, E. S. (2018). Biosynthesis of redox-active metabolites in response to iron deficiency in plants. Nat. Chem. Biol. 14, 442-450. doi: 10.1038/s41589-018-0019-2

Rascovan, N., Carbonetto, B., Perrig, D., Diaz, M., Canciani, W., Abalo, M., et al. (2016). Integrated analysis of root microbiomes of soybean and wheat from agricultural fields. Sci. Rep. 6, 28084. doi: 10.1038/srep28084

Reinhold-Hurek, B., Bunger, W., Burbano, C. S., Sabale, M., and Hurek, T. (2015). Roots shaping their microbiome: global hotspots for microbial activity. Annu. Rev. Phytopathol. 53, 403-424. doi: 10.1146/annurev-phyto-082712-102342

Robbins, C., Thiergart, T., Hacquard, S., Garrido-Oter, R., Gans, W., Peiter, E., et al. (2018). Root-associated bacterial and fungal community profiles of Arabidopsis thaliana are robust across contrasting soil P levels. Phytobiomes J. 2, 24-34. doi: 10.1094/PBIOMES-09-17-0042-R

Robertson-Albertyn, S., Alegria Terrazas, R., Balbirnie, K., Blank, M., Janiak, A., Szarejko, I., et al. (2017). Root hair mutations displace the barley rhizosphere microbiota. Front. Plant Sci. 8, 1094. doi: 10.3389/fpls.2017.01094

Rodriguez, P. A., Rothballer, M., Chowdhury, S. P., Nussbaumer, T., Gutjahr, C., and Falter-Braun, P. (2019). Systems biology of plant-microbiome interactions. Mol. Plant 12, 804-821. doi: 10.1016/j.molp.2019.05.006

Rodriguez-Celma, J., Lin, W. D., Fu, G. M., Abadia, J., Lopez-Millan, A. F., and Schmidt, W. (2013). Mutually exclusive alterations in secondary metabolism are critical for the uptake of insoluble iron compounds by Arabidopsis and Medicago truncatula. Plant Physiol. 162, 1473-1485. doi: 10.1104/ pp.113.220426

Rolli, E., Marasco, R., Vigani, G., Ettoumi, B., Mapelli, F., Deangelis, M. L., et al. (2015). Improved plant resistance to drought is promoted by the rootassociated microbiome as a water stress-dependent trait. Environ. Microbiol. 17, 316-331. doi: 10.1111/1462-2920.12439

Rudrappa, T., Czymmek, K. J., Pare, P. W., and Bais, H. P. (2008). Root-secreted malic acid recruits beneficial soil bacteria. Plant Physiol. 148, 1547-1556. doi: 10.1104/pp.108.127613

Santhanam, R., Luu, V. T., Weinhold, A., Goldberg, J., Oh, Y., and Baldwin, I. T. (2015). Native root-associated bacteria rescue a plant from a sudden-wilt disease that emerged during continuous cropping. Proc. Natl. Acad. Sci. U.?S.? A. 112, 5013-5020. doi: 10.1073/pnas.1505765112

Sasse, J., Martinoia, E., and Northen, T. (2017). Feed your friends: do plant exudates shape the root microbiome? Trends Plant Sci. 23, 25-41. doi: 10.1016/ j.tplants.2017.09.003

Schafer, P., Pfiffi, S., Voll, L. M., Zajic, D., Chandler, P. M., Waller, F., et al. (2009). Manipulation of plant innate immunity and gibberellin as factor of compatibility in the mutualistic association of barley roots with Piriformospora indica. Plant J. 59, 461-474. doi: 10.1111/j.1365313X.2009.03887.x

Schlaeppi, K., Dombrowski, N., Garrido-Oter, R., Ver Loren Van Themaat, E., and Schulze-Lefert, P. (2014). Quantitative divergence of the bacterial root microbiota in Arabidopsis thaliana relatives. Proc. Natl. Acad. Sci. U. S. A. 111, 585-592. doi: 10.1073/pnas.1321597111

Schlatter, D., Kinkel, L., Thomashow, L., Weller, D., and Paulitz, T. (2017). Disease suppressive soils: new insights from the soil microbiome. Phytopathology 107, 1284-1297. doi: 10.1094/PHYTO-03-17-0111-RVW

Schmid, N. B., Giehl, R. F., Doll, S., Mock, H. P., Strehmel, N., Scheel, D., et al. (2014). Feruloyl-CoA 6'-Hydroxylase1-dependent coumarins mediate iron acquisition from alkaline substrates in Arabidopsis. Plant Physiol. 164, 160172. doi: 10.1104/pp.113.228544

Schmidt, H., Gunther, C., Weber, M., Sporlein, C., Loscher, S., Bottcher, C., et al. (2014). Metabolome analysis of Arabidopsis thaliana roots identifies a key metabolic pathway for iron acquisition. PloS One 9, e102444. doi: 10.1371/ journal.pone.0102444
Schoch, C. L., Seifert, K. A., Huhndorf, S., Robert, V., Spouge, J. L., Levesque, C. A., et al. (2012). Nuclear ribosomal internal transcribed spacer (ITS) region as a universal DNA barcode marker for Fungi. Proc. Natl. Acad. Sci. U. S. A. 109, 6241-6246. doi: 10.1073/pnas.1117018109

Senthil-Kumar, M., and Mysore, K. S. (2013). Nonhost resistance against bacterial pathogens: retrospectives and prospects. Annu. Rev. Phytopathol. 51, 407-427. doi: 10.1146/annurev-phyto-082712-102319

Sessitsch, A., Hardoim, P., Doring, J., Weilharter, A., Krause, A., Woyke, T., et al. (2012). Functional characteristics of an endophyte community colonizing rice roots as revealed by metagenomic analysis. Mol. Plant-Microbe Interact. 25, 28-36. doi: 10.1094/MPMI-08-11-0204

Sessitsch, A., Pfaffenbichler, N., and Mitter, B. (2019). Microbiome applications from lab to field: Facing complexity. Trends Plant Sci. 24, 194-198. doi: 10.1016/j.tplants.2018.12.004

Shakya, M., Gottel, N., Castro, H., Yang, Z. K., Gunter, L., Labbe, J., et al. (2013). A multifactor analysis of fungal and bacterial community structure in the root microbiome of mature Populus deltoides trees. PloS One 8, e76382. doi: 10.1371/journal.pone.0076382

Sharpton, T. J. (2014). An introduction to the analysis of shotgun metagenomic data. Front. Plant Sci. 5, 209. doi: 10.3389/fpls.2014.00209

Shi, W., Li, M., Wei, G., Tian, R., Li, C., Wang, B., et al. (2019). The occurrence of potato common scab correlates with the community composition and function of the geocaulosphere soil microbiome. Microbiome 7, 14. doi: 10.1186/s40168019-0629-2

Shoresh, M., Harman, G. E., and Mastouri, F. (2010). Induced systemic resistance and plant responses to fungal biocontrol agents. Annu. Rev. Phytopathol. 48, 21-43. doi: 10.1146/annurev-phyto-073009-114450

Siegel-Hertz, K., Edel-Hermann, V., Chapelle, E., Terrat, S., Raaijmakers, J. M., and Steinberg, C. (2018). Comparative microbiome analysis of a Fusarium wilt suppressive soil and a Fusarium wilt conducive soil from the Chateaurenard region. Front. Microbiol. 9, 568. doi: 10.3389/fmicb.2018.00568

Snelders, N. C., Kettles, G. J., Rudd, J. J., and Thomma, B. P. H. J. (2018). Plant pathogen effector proteins as manipulators of host microbiomes? Mol. Plant Pathol. 19, 257-259. doi: 10.1111/mpp.12628

Steinkellner, S., Mammerler, R., and Vierheilig, H. (2005). Microconidia germination of the tomato pathogen Fusarium oxysporum in the presence of root exudates. J. Plant Interact. 1, 23-30. doi: 10.1080/ 17429140500134334

Stringlis, I. A., Proietti, S., Hickman, R., Van Verk, M. C., Zamioudis, C., and Pieterse, C. M. J. (2018a). Root transcriptional dynamics induced by beneficial rhizobacteria and microbial immune elicitors reveal signatures of adaptation to mutualists. Plant J. 93, 166-180. doi: 10.1111/tpj.13741

Stringlis, I. A., Yu, K., Feussner, K., De Jonge, R., Van Bentum, S., Van Verk, M. C., et al. (2018b). MYB72-dependent coumarin exudation shapes root microbiome assembly to promote plant health. Proc. Natl. Acad. Sci. U. S. A. 115, E5213E5222. doi: 10.1073/pnas.1722335115

Stringlis, I. A., Zhang, H., Pieterse, C. M. J., Bolton, M. D., and De Jonge, R. (2018c). Microbial small molecules - weapons of plant subversion. Natural Product Rep. 35, 410-433. doi: 10.1039/c7np00062f

Stringlis, I. A., De Jonge, R., and Pieterse, C. M. J. (2019a). The age of coumarins in plant-microbe interactions. Plant Cell Physiol. 60, 1405-1419. doi: 10.1093/ pcp/pcz076

Stringlis, I. A., Zamioudis, C., Berendsen, R. L., Bakker, P. A. H. M., and Pieterse, C. M. J. (2019b). Type III secretion system of beneficial rhizobacteria Pseudomonas simiae WCS417 and Pseudomonas defensor WCS374. Front. Microbiol. 10, 1631. doi: 10.3389/fmicb.2019.01631

Subramanian, S., Stacey, G., and Yu, O. (2007). Distinct, crucial roles of flavonoids during legume nodulation. Trends In Plant Sci. 12, 282-285. doi: 10.1016/ j.tplants.2007.06.006

Thimmappa, R., Geisler, K., Louveau, T., O'maille, P., and Osbourn, A. (2014). Triterpene biosynthesis in plants. Annu. Rev. Plant Biol. 65, 225-257. doi: 10.1146/annurev-arplant-050312-120229

Tsai, H. H., and Schmidt, W. (2017a). Mobilization of iron by plant-borne coumarins. Trends Plant Sci. 22, 538-548. doi: 10.1016/j.tplants.2017.03.008

Tsai, H. H., and Schmidt, W. (2017b). One way. Or another? Iron uptake in plants. New Phytol. 214, 500-505. doi: 10.1111/nph.14477 
Tsai, H. H., Rodriguez-Celma, J., Lan, P., Wu, Y. C., Velez-Bermudez, I. C., and Schmidt, W. (2018). Scopoletin 8-hydroxylase-mediated fraxetin production is crucial for iron mobilization. Plant Physiol. 177, 194-207. doi: 10.1104/ pp. 18.00178

Tsolakidou, M.-D., Stringlis, I. A., Fanega-Sleziak, N., Papageorgiou, S., Tsalakou, A., and Pantelides, I. S. (2019a). Rhizosphere-enriched microbes as a pool to design synthetic communities for reproducible beneficial outputs. FEMS Microbiol. Ecol. 95, fiz138. doi: 10.1093/femsec/fiz138

Tsolakidou, M. D., Pantelides, I. S., Tzima, A. K., Kang, S., Paplomatas, E. J., and Tsaltas, D. (2019b). Disruption and overexpression of the gene encoding ACC (1-aminocyclopropane-1-carboxylic acid) deaminase in soil-borne fungal pathogen Verticillium dahliae revealed the role of ACC as a potential regulator of virulence and plant defense. Mol. Plant-Microbe Interact. 32, 639-653. doi: 10.1094/MPMI-07-18-0203-R

Turner, T. R., Ramakrishnan, K., Walshaw, J., Heavens, D., Alston, M., Swarbreck, D., et al. (2013). Comparative metatranscriptomics reveals kingdom level changes in the rhizosphere microbiome of plants. ISME J. 7, 2248-2258. doi: 10.1038/ ismej.2013.119

Turrà, D., El Ghalid, M., Rossi, F., and Di Pietro, A. (2015). Fungal pathogen uses sex pheromone receptor for chemotropic sensing of host plant signals. Nature 527, 521-524. doi: 10.1038/nature15516

Van Dam, N. M., and Bouwmeester, H. J. (2016). Metabolomics in the rhizosphere: Tapping into belowground chemical communication. Trends Plant Sci. 21, 256-265. doi: 10.1016/j.tplants.2016.01.008

Van De Mortel, J. E., Schat, H., Moerland, P. D., Ver Loren Van Themaat, E., Van Der Ent, S., Blankestijn, H., et al. (2008). Expression differences for genes involved in lignin, glutathione and sulphate metabolism in response to cadmium in Arabidopsis thaliana and the related $\mathrm{Zn} / \mathrm{Cd}$-hyperaccumulator Thlaspi caerulescens. Plant Cell Environ. 31, 301-324. doi: 10.1111/j.13653040.2007.01764.x

Van Der Ent, S., Verhagen, B. W., Van Doorn, R., Bakker, D., Verlaan, M. G., Pel, M. J., et al. (2008). MYB72 is required in early signaling steps of rhizobacteriainduced systemic resistance in Arabidopsis. Plant Physiol. 146, 1293-1304. doi: 10.1104/pp.107.113829

Van Der Heijden, M. G., and Hartmann, M. (2016). Networking in the plant microbiome. PloS Biol. 14, e1002378. doi: 10.1371/journal.pbio.1002378

Van West, P., Appiah, A. A., and Gow, N. A. R. (2003). Advances in research on oomycete root pathogens. Physiol. Mol. Plant Pathol. 62, 99-113. doi: 10.1016/ S0885-5765(03)00044-4

Vandenkoornhuyse, P., Mahe, S., Ineson, P., Staddon, P., Ostle, N., Cliquet, J. B., et al. (2007). Active root-inhabiting microbes identified by rapid incorporation of plant-derived carbon into RNA. Proc. Natl. Acad. Sci. U. S. A. 104, 1697016975. doi: 10.1073/pnas.0705902104

Vandenkoornhuyse, P., Quaiser, A., Duhamel, M., Le Van, A., and Dufresne, A. (2015). The importance of the microbiome of the plant holobiont. New Phytol. 206, 1196-1206. doi: 10.1111/nph.13312

Vannier, N., Agler, M., and Hacquard, S. (2019). Microbiota-mediated disease resistance in plants. PloS Pathog. 15, e1007740. doi: 10.1371/ journal.ppat.1007740

Ventorino, V., Pascale, A., Fagnano, M., Adamo, P., Faraco, V., Rocco, C., et al. (2019). Soil tillage and compost amendment promote bioremediation and biofertility of polluted area. J. Cleaner Prod. 239, 118087. doi: 10.1016/ j.jclepro.2019.118087

Verbon, E. H., and Liberman, L. M. (2016). Beneficial microbes affect endogenous mechanisms controlling root development. Trends Plant Sci. 21, 218-229. doi: 10.1016/j.tplants.2016.01.013

Verbon, E. H., Trapet, P. L., Stringlis, I. A., Kruijs, S., Bakker, P. A. H. M., and Pieterse, C. M. J. (2017). Iron and immunity. Annu. Rev. Phytopathol. 55, 355-375. doi: 10.1146/annurev-phyto-080516-035537

Verhagen, B. W., Glazebrook, J., Zhu, T., Chang, H. S., Van Loon, L. C., and Pieterse, C. M. J. (2004). The transcriptome of rhizobacteria-induced systemic resistance in Arabidopsis. Mol. Plant-Microbe Interact. 17, 895-908. doi: 10.1094/MPMI.2004.17.8.895

Vicre, M., Santaella, C., Blanchet, S., Gateau, A., and Driouich, A. (2005). Root border-like cells of Arabidopsis. Microscopical characterization and role in the interaction with rhizobacteria. Plant Physiol. 138, 998-1008. doi: 10.1104/ pp.104.051813
Viterbo, A., Landau, U., Kim, S., Chernin, L., and Chet, I. (2010). Characterization of ACC deaminase from the biocontrol and plant growth-promoting agent Trichoderma asperellum T203. FEMS Microbiol. Lett. 305, 42-48. doi: 10.1111/ j.1574-6968.2010.01910.x

Voges, M., Bai, Y., Schulze-Lefert, P., and Sattely, E. S. (2019). Plant-derived coumarins shape the composition of an Arabidopsis synthetic root microbiome. Proc. Natl. Acad. Sci. U.S.A. 116, 12558-12565. doi: 10.1073/ pnas. 1820691116

Vorholt, J. A., Vogel, C., Carlstrom, C. I., and Muller, D. B. (2017). Establishing causality: opportunities of synthetic communities for plant microbiome research. Cell Host Microbe 22, 142-155. doi: 10.1016/j.chom.2017.07.004

Vos, I. A., Pieterse, C. M. J., and Van Wees, S. C. M. (2013). Costs and benefits of hormone-regulated plant defences. Plant Pathol. 62, 43-55. doi: 10.1111/ ppa. 12105

Wachsman, G., Sparks, E. E., and Benfey, P. N. (2015). Genes and networks regulating root anatomy and architecture. New Phytol. 208, 26-38. doi: 10.1111/nph.13469

Wang, L., Albert, M., Einig, E., Furst, U., Krust, D., and Felix, G. (2016). The pattern-recognition receptor CORE of Solanaceae detects bacterial cold-shock protein. Nat. Plants 2, 16185. doi: 10.1038/nplants.2016.185

Wei, Z., Yang, T., Friman, V.P., Xu, Y., Shen, Q., and Jousset, A. (2015). Trophic network architecture of root-associated bacterial communities determines pathogen invasion and plant health. Nat. Commun. 6, 8413. doi: 10.1038/ncomms9413

Wei, Z., Gu, Y., Friman, V. P., Kowalchuk, G. A., Xu, Y., Shen, Q., et al. (2019). Initial soil microbiome composition and functioning predetermine future plant health. Sci. Adv. 5, eaaw0759. doi: 10.1126/sciadv.aaw0759

Weiss, M., Waller, F., Zuccaro, A., and Selosse, M. A. (2016). Sebacinales - one thousand and one interactions with land plants. New Phytol. 211, 20-40. doi: 10.1111/nph.13977

Weller, D. M., Raaijmakers, J. M., Gardener, B. B., and Thomashow, L. S. (2002). Microbial populations responsible for specific soil suppressiveness to plant pathogens. Annu. Rev. Phytopathol. 40, 309-348. doi: 10.1146/ annurev.phyto.40.030402.110010

Wintermans, P. C., Bakker, P. A. H. M., and Pieterse, C. M. J. (2016). Natural genetic variation in Arabidopsis for responsiveness to plant growth-promoting rhizobacteria. Plant Mol. Biol. 90, 623-634. doi: 10.1007/s11103-016-0442-2

Wyrsch, I., Dominguez-Ferreras, A., Geldner, N., and Boller, T. (2015). Tissuespecific FLAGELLIN-SENSING 2 (FLS2) expression in roots restores immune responses in Arabidopsis fls2 mutants. New Phytol. 206, 774-784. doi: 10.1111/ nph. 13280

Xie, F., Williams, A., Edwards, A., and Downie, J. A. (2012). A plant arabinogalactan-like glycoprotein promotes a novel type of polar surface attachment by Rhizobium leguminosarum. Mol. Plant-Microbe Interact. 25, 250-258. doi: 10.1094/MPMI-08-11-0211

Xu, D., Hanschen, F. S., Witzel, K., Nintemann, S. J., Nour-Eldin, H. H., Schreiner, M., et al. (2017). Rhizosecretion of stele-synthesized glucosinolates and their catabolites requires GTR-mediated import in Arabidopsis. J. Exp. Bot. 68, 3205-3214. doi: 10.1093/jxb/erw355

Yadav, V., Kumar, M., Deep, D. K., Kumar, H., Sharma, R., Tripathi, T., et al. (2010). A phosphate transporter from the root endophytic fungus Piriformospora indica plays a role in phosphate transport to the host plant. J. Biol. Chem. 285, 26532-26544. doi: 10.1074/jbc.M110.111021

Yadeta, K. A., and Thomma, B. P. H. J. (2013). The xylem as battleground for plant hosts and vascular wilt pathogens. Front. Plant Sci. 4, 97. doi: 10.3389/ fpls.2013.00097

Yang, J., Kloepper, J. W., and Ryu, C. M. (2009). Rhizosphere bacteria help plants tolerate abiotic stress. Trends Plant Sci. 14, 1-4. doi: 10.1016/j.tplants. 2008.10.004

Yang, J. W., Yi, H. S., Kim, H., Lee, B., Lee, S., Ghim, S. Y., et al. (2011). Whitefly infestation of pepper plants elicits defence responses against bacterial pathogens in leaves and roots and changes the below-ground microflora. J.? Ecol. 99, 46-56. doi: 10.1111/j.1365-2745.2010.01756.x

Yu, K., Pieterse, C. M. J., Bakker, P. A. H. M., and Berendsen, R. L. (2019a). Beneficial microbes going underground of root immunity. Plant Cell Environ. 42, 2860-2870. doi: 10.1111/pce.13632

Yu, K., Tichelaar, R., Liu, Y., Savant, N., Lagendijk, E., Van Kuijk, S., et al. (2019b). Rhizopshere-associated Pseudomonas suppress local root immune responses 
by gluconic acid-mediated lowering of environmental pH. Curr. Biol. 29, 39133920. doi: 10.1016/j.cub.2019.09.015

Yuan, J., Zhao, J., Wen, T., Zhao, M., Li, R., Goossens, P., et al. (2018). Root exudates drive the soil-borne legacy of aboveground pathogen infection. Microbiome 6, 156. doi: 10.1186/s40168-018-0537-x

Zamioudis, C., and Pieterse, C. M. J. (2012). Modulation of host immunity by beneficial microbes. Mol. Plant-Microbe Interact. 25, 139-150. doi: 10.1094/ MPMI-06-11-0179

Zamioudis, C., Hanson, J., and Pieterse, C. M. J. (2014). B-Glucosidase BGLU42 is a MYB72-dependent key regulator of rhizobacteria-induced systemic resistance and modulates iron deficiency responses in Arabidopsis roots. New Phytol. 204, 368-379. doi: 10.1111/nph.12980

Zamioudis, C., Korteland, J., Van Pelt, J. A., Van Hamersveld, M., Dombrowski, N., Bai, Y., et al. (2015). Rhizobacterial volatiles and photosynthesis-related signals coordinate MYB72 expression in Arabidopsis roots during onset of induced systemic resistance and iron-deficiency responses. Plant J. 84, 309322. doi: 10.1111/tpj.12995

Zeilinger, S., Gupta, V. K., Dahms, T. E., Silva, R. N., Singh, H. B., Upadhyay, R. S., et al. (2016). Friends or foes? Emerging insights from fungal interactions with plants. FEMS Microbiol. Rev. 40, 182-207. doi: 10.1093/femsre/fuv045

Zelezniak, A., Andrejev, S., Ponomarova, O., Mende, D. R., Bork, P., and Patil, K. R. (2015). Metabolic dependencies drive species co-occurrence in diverse microbial communities. Proc. Natl. Acad. Sci. U. S. A. 112, 6449-6454. doi: 10.1073/ pnas. 1421834112

Zgadzaj, R., Garrido-Oter, R., Jensen, D. B., Koprivova, A., Schulze-Lefert, P., and Radutoiu, S. (2016). Root nodule symbiosis in Lotus japonicus drives the establishment of distinctive rhizosphere, root, and nodule bacterial communities. Proc. Natl. Acad. Sci. U. S. A. 113, 7996-8005. doi: 10.1073/ pnas. 1616564113

Zhalnina, K., Louie, K. B., Hao, Z., Mansoori, N., Da Rocha, U. N., Shi, S., et al. (2018). Dynamic root exudate chemistry and microbial substrate preferences drive patterns in rhizosphere microbial community assembly. Nat. Microbiol. 3, 470-480. doi: 10.1038/s41564-018-0129-3

Zhang, Y., Xu, J., Riera, N., Jin, T., Li, J., and Wang, N. (2017). Huanglongbing impairs the rhizosphere-to-rhizoplane enrichment process of the citrus rootassociated microbiome. Microbiome 5, 97. doi: 10.1186/s40168-017-0304-4

Zhou, C., Guo, J., Zhu, L., Xiao, X., Xie, Y., Zhu, J., et al. (2016). Paenibacillus polymyxa BFKC01 enhances plant iron absorption via improved root systems and activated iron acquisition mechanisms. Plant Physiol. Biochem. 105, 162-173. doi: 10.1016/j.plaphy.2016.04.025

Conflict of Interest: The authors declare that the research was conducted in the absence of any commercial or financial relationships that could be construed as a potential conflict of interest.

Copyright (c) 2020 Pascale, Proietti, Pantelides and Stringlis. This is an open-access article distributed under the terms of the Creative Commons Attribution License (CC $B Y)$. The use, distribution or reproduction in other forums is permitted, provided the original author(s) and the copyright owner(s) are credited and that the original publication in this journal is cited, in accordance with accepted academic practice. No use, distribution or reproduction is permitted which does not comply with these terms. 